\title{
Technological change impact on some social values of rural youth in Assiut governorate, Egypt
}

\author{
Abdallha A. R.*, Khalefa E. A. A., Abdel Hafez M. M. I. \\ Department of Agricultural Extension \& Rural Sociology, Faculty of Agriculture, Al-Azhar University, Assiut, Egypt
}

\begin{abstract}
Research mainly aimed to determine the degree of use of the rural youth respondents to social networking sites, and to determine the level of change in the studied social values in light of the respondents' use of social access sites, and to determine the relationship between the degree of the respondents' use of social networking sites and the level of change in the studied social values. Research was conducted in Assiut governorate, Egypt as a geographical area; and Five administrative centers were choose in a random way, Dayrut Center, Sadafa Center, Sahel Saleem Center, Al-Ghanayem Center, and Assiut Center, two villages were randomly selected from each center: Sanbo and Dachlot villages in Deirout center, Awlad Elias and Majris villages in Sedfa center, Al Matamr and Al-Awnah vellages in Sahel Saleem center, Deir Al Janadla and Al-Masha'a Bahri vellages in Ghanaim center, Manqbad and Mosha vellages in Assiut Center, and accordingly the number of young pepole in the selected villages was counted and their number reached 48024, it reached 382 respondents, and the table, frequencies and percentages were used to display the data. Spearman's rank correlation coefficient was also used to determine the relationship between the degree of the respondents' use of social networking sites and the level of change in the studied social values, through the Statistical Program for Social Sciences (SPSS). Research several results, the most important of which are the following:
\end{abstract}

1. That slightly more than half of the respondents (51\%) had a medium degree of use of social networking sites, and nearly a third $(28.5 \%)$ had a low degree of use, and just over a fifth $(20.5 \%)$ The respondents had a high degree of use of these sites.

2. Results also showed that the level of change in social values was average for more than half (54.7\%) of the respondents, high for nearly a third $(31.9 \%)$ of the respondents, and low for more than one tenth $(13.4 \%)$ of the respondents.

Keywords: technological change, social values, rural youth, Assiut.

* Corresponding author: Abdallha A. R.,

E-mail address: abdo669392@gmail.com 


\title{
أثز التحول التكنولوجي على بعض القيم الاجتماعية للشباب الريفي بمحافظة أسيوط بجمهورية مصر العربية
}

\author{
عبده رمضان عبدالله جمعة ، إبر اهيم عبدالرحمن علي خليفة ، محمد محمد إسماعيل عبدالحافظ \\ قسم الإرشاد الزر اعي و المجتمع الريفي ، كلية الزراعة ، جامعة الأزهر (فرع أسيوط) ، أسيوط ، جمهورية مصر العربية
}

المستخلص

استهدف البحث تحديد درجة استخدام الثباب الريفي المبحوثين لمواقع التواصل الاجتماعي، وتحديد مستوى التغير في القيم الاجتماعية

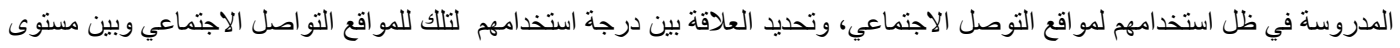

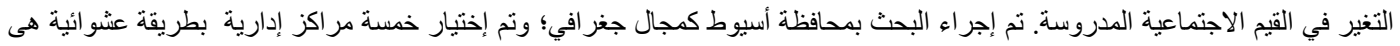

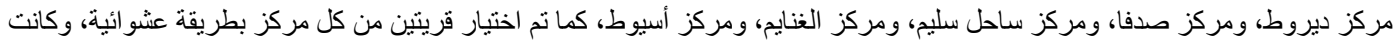

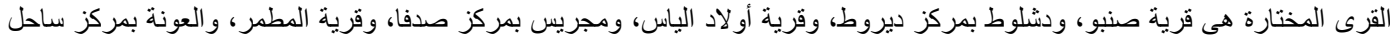

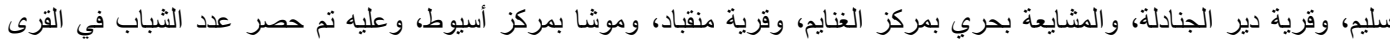

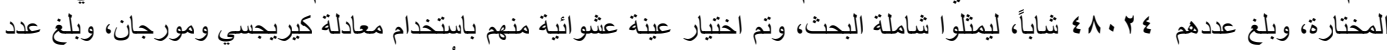

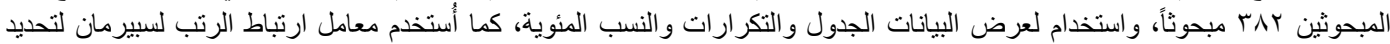

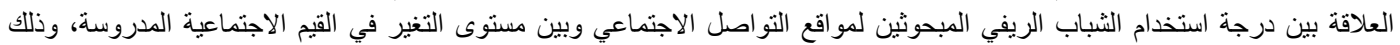

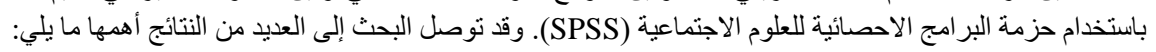

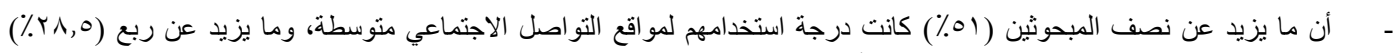

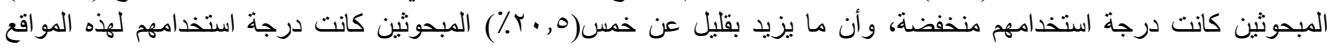

مرتفعة.

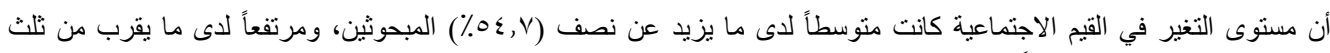

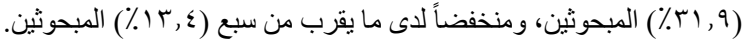

كلمات دالة: النحول التكنولوجي ، القيم الاجتماعية ، الثباب الريفي ، أسيوط. 


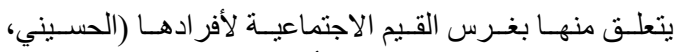

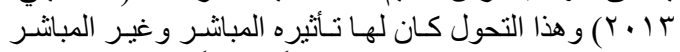

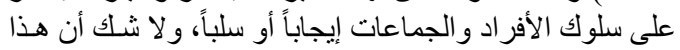

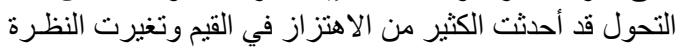

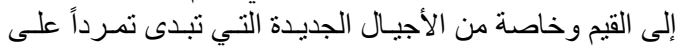

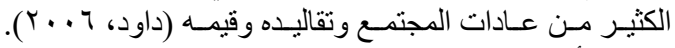

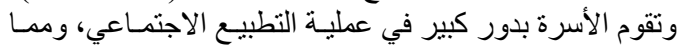

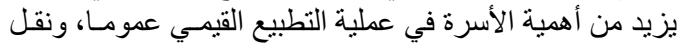

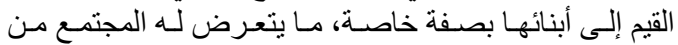

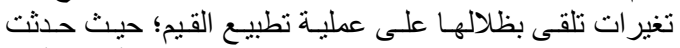

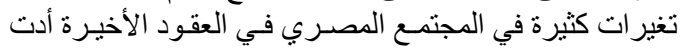

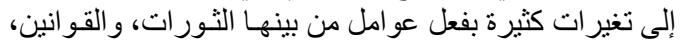

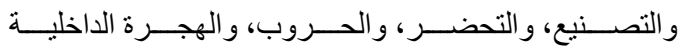

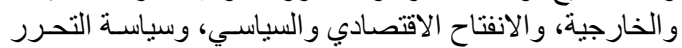

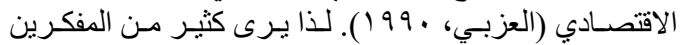

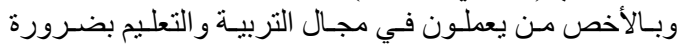

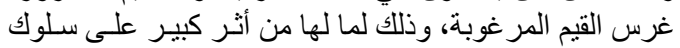

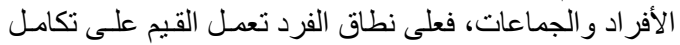

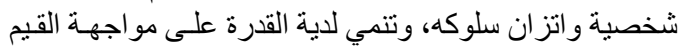

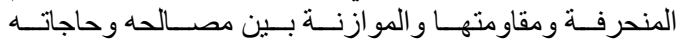

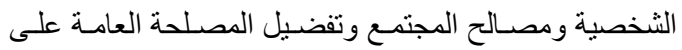

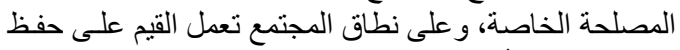

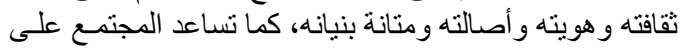

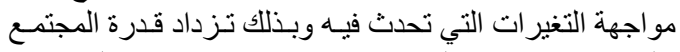

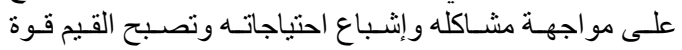

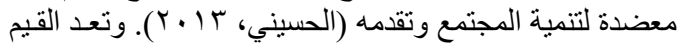

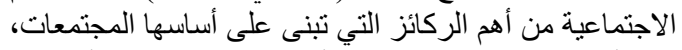

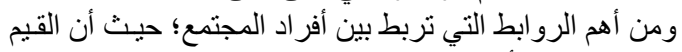

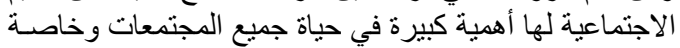

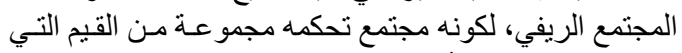

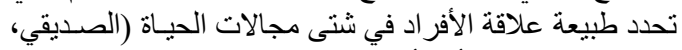

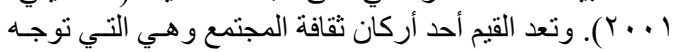

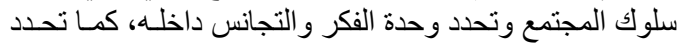

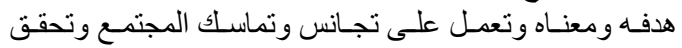

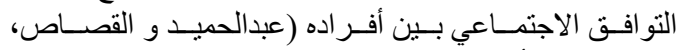

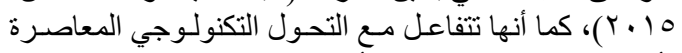

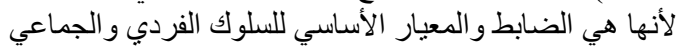

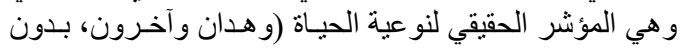

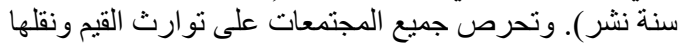

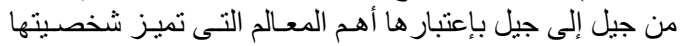

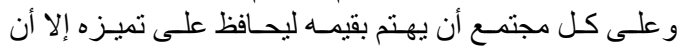

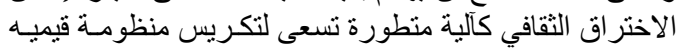

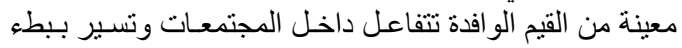

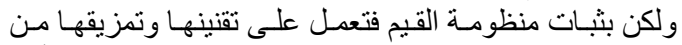

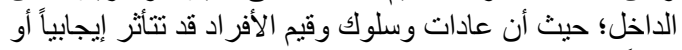

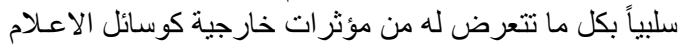

\section{مقدمة البحث ومشكثته}

يعيش العالم اليوم حالة من التحـولات الاقتصـادية والاجتماعيـة

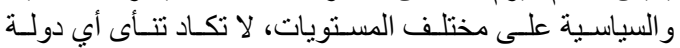

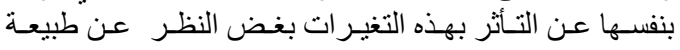

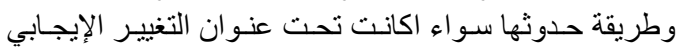

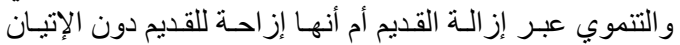

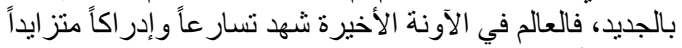

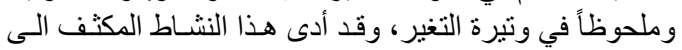

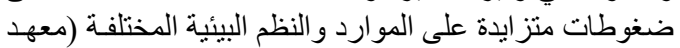

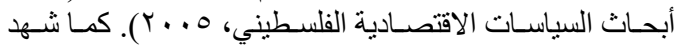

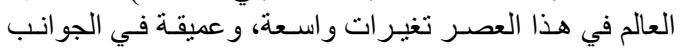

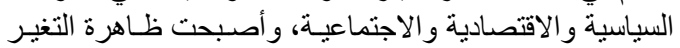

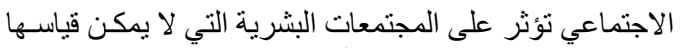

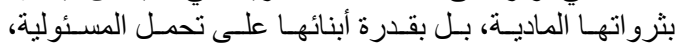

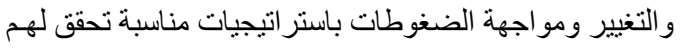

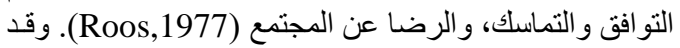

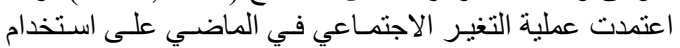

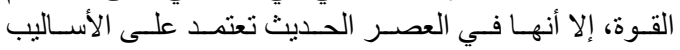

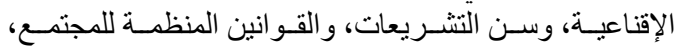

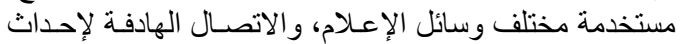

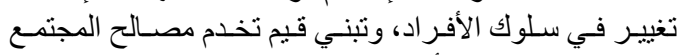

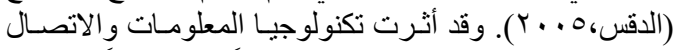

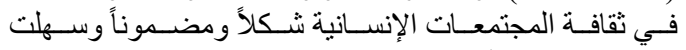

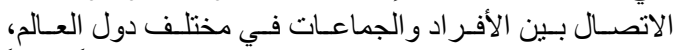

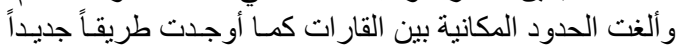

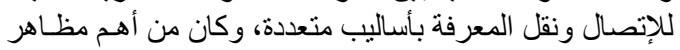

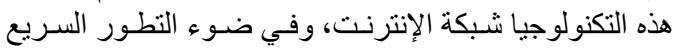

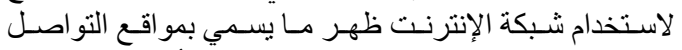

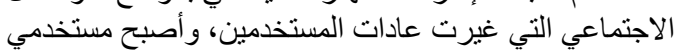

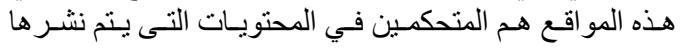

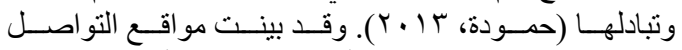
الاجتماعي في الآونة الآخيرة أنها تسيطر على ولى أفكار الثباب؛

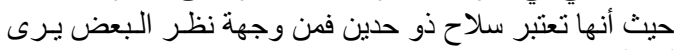

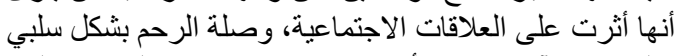

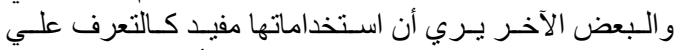

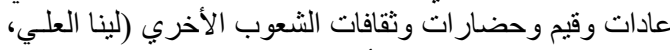

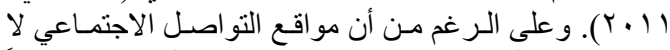

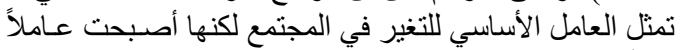

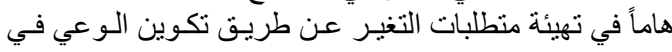

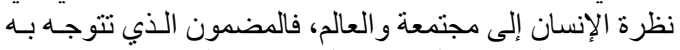

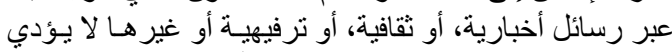

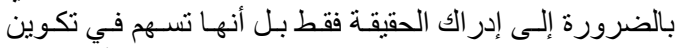

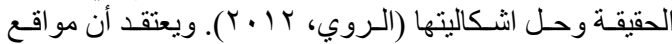
التواصل الاجتماعي كان لهـا بعض الآثـار الإيجابيـة و السـليية

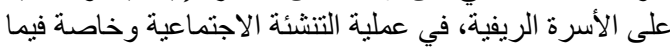




\section{الطريقة البحثية

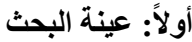

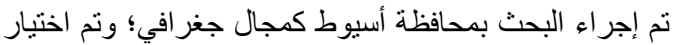

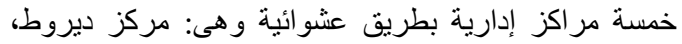

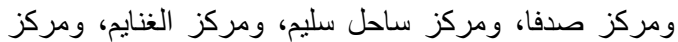

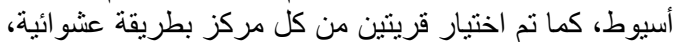

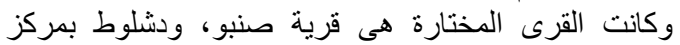

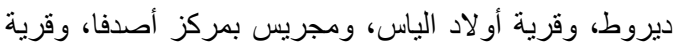

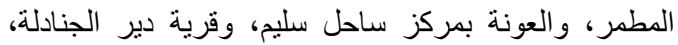

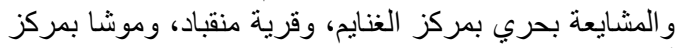

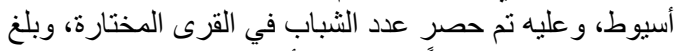

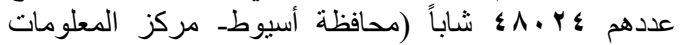

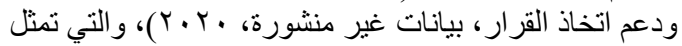

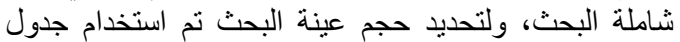

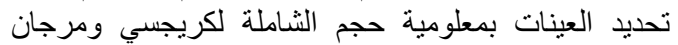
(Krejcie and Morgan, 1970) جمع البيانات من المبحوثين باستخدام استمارة استبيان أعدات

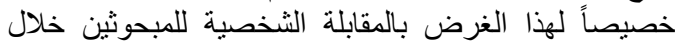

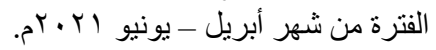

ثانياً: المعالجة الكمية للمتغيرات البحثية

المتغيرات المستقلة

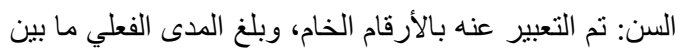

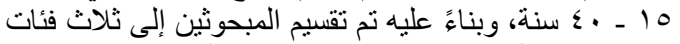

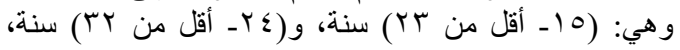

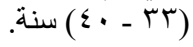

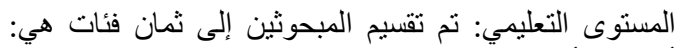

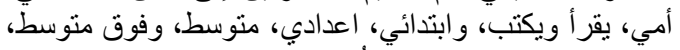

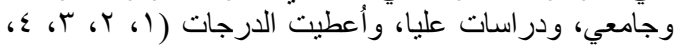

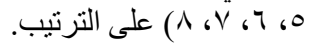

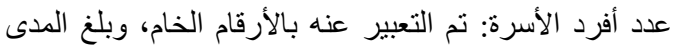

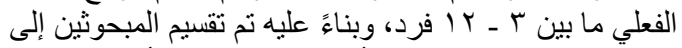

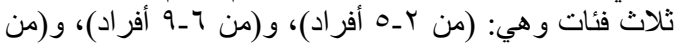

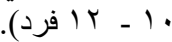

منوسط دخل الأسرة الثهري: نم التعبير عنه بالأرقام الخام،

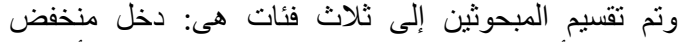

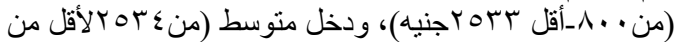
ح

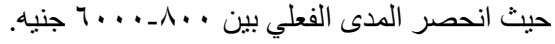

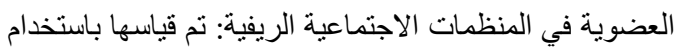

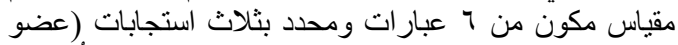

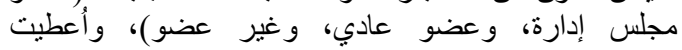

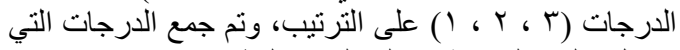

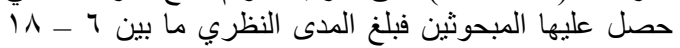

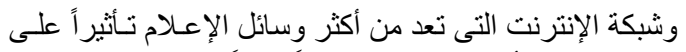

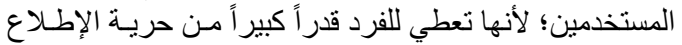

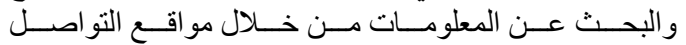

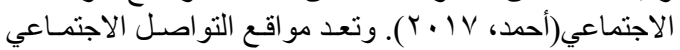

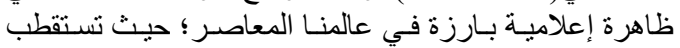

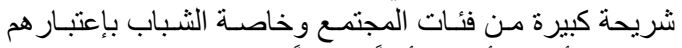

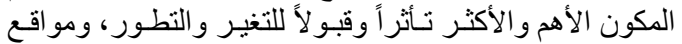

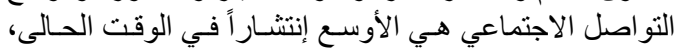

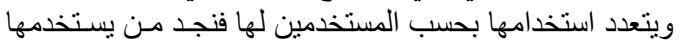

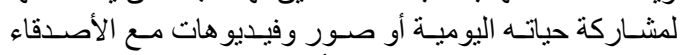

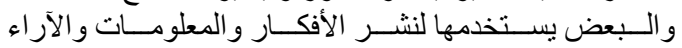

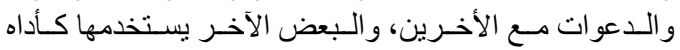

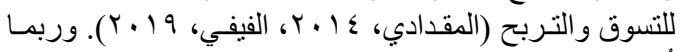

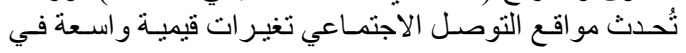

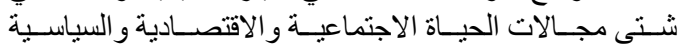

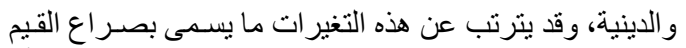

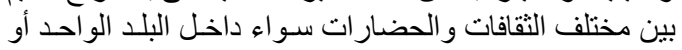

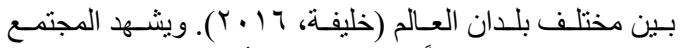

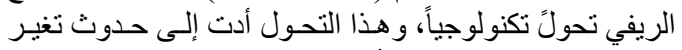

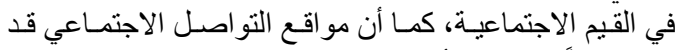

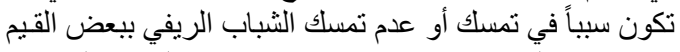

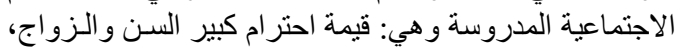

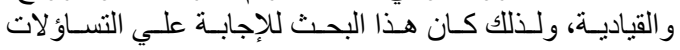

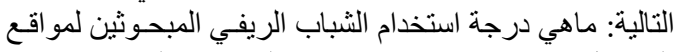

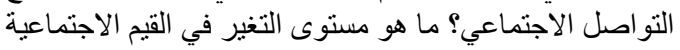

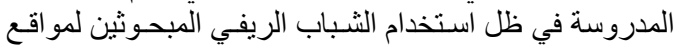

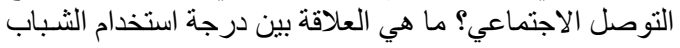

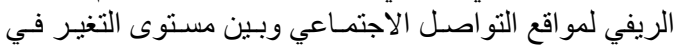
القيم الاجتماعية المدروسة؛ التو اصني

\section{أهداف البحث}

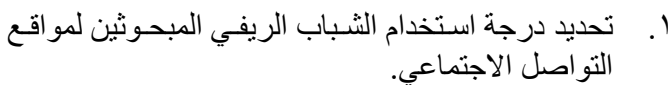

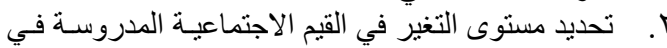

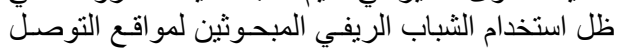
الاجنماعي.

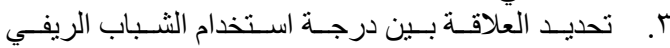

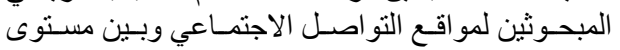
التغير في القيم الاجتماعية المدروسة.

\section{الفرض البحثي}

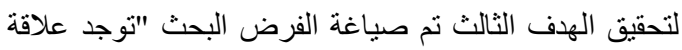

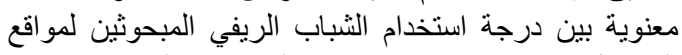
التواصل الاجتماعي وبين مستوى التغير في القيم الاجتماعية

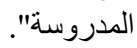




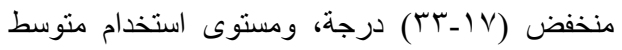

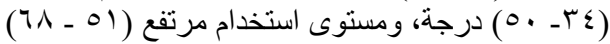

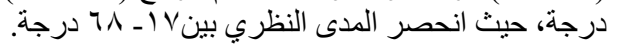

ثانياً: تحديا مستوى التغير في القيم الاجتماعية تم قياسه باستقصاء رأى المبحوثين فى التغير في ثلاث قيم

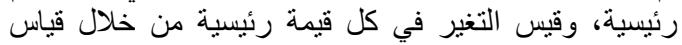

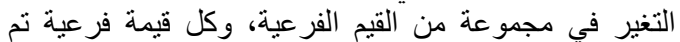

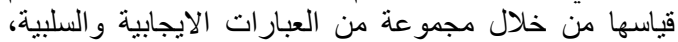

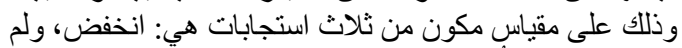

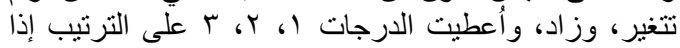

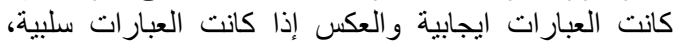

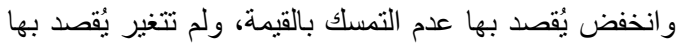

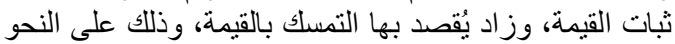

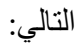

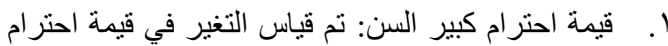

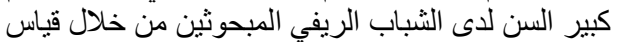

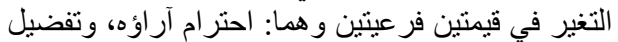

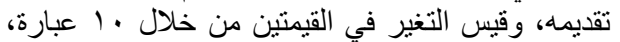
موز عة على النحو التالي: التئي

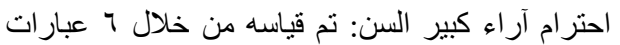

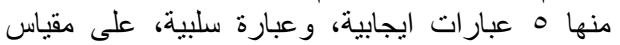

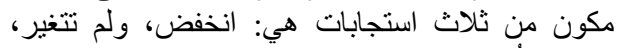

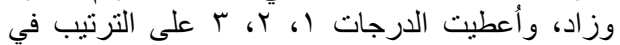

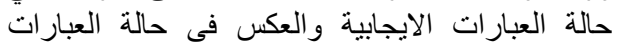

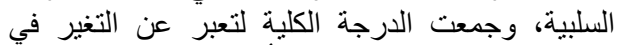

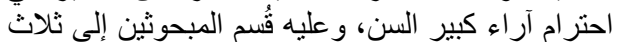
فئات هي: عدم التمسك بالقيمة (من آن 7 - 9 درجة)، التى

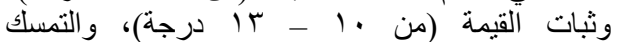

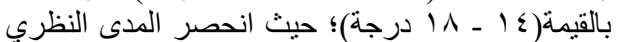

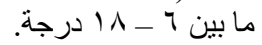

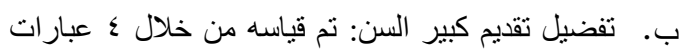

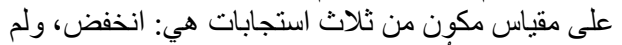

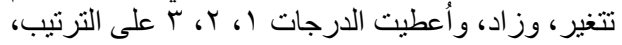

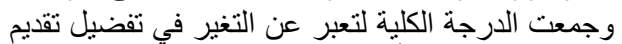

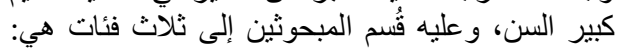

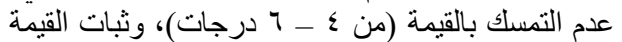

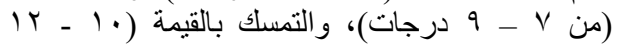

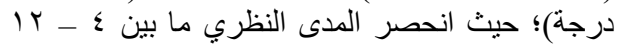
درجة.

أما عن مستوى التغير في قيمة احترام كبير السن إجمالاً تم

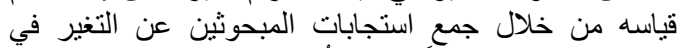

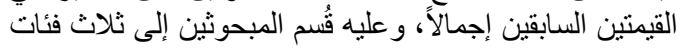

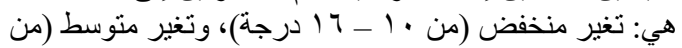
ان - IV

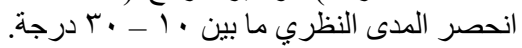

درجة، وبناءً عليه تم تقيم المبحوثين وفقاً لعضويتهم فى العي

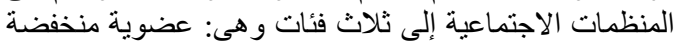

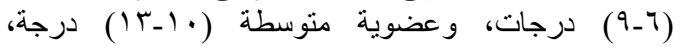

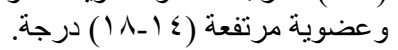

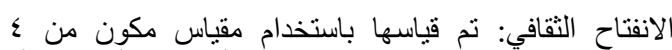

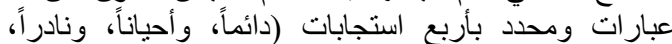

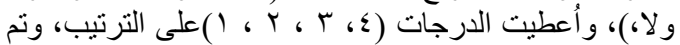

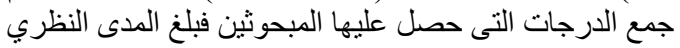

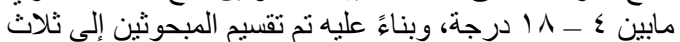

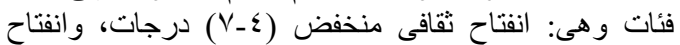

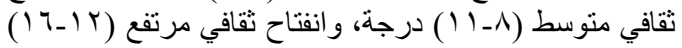
درجة.

المتغيرات التابعة

أولا: تحديد درجة استخدام الثباب الريفي لمواقع التواصل الاجتماعي

تم قياسه من خلال توجيه بعض الاسئلة للمبحوثين و هي:

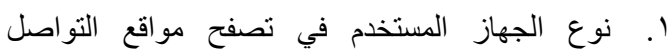
الاجتماعي: تم قياسه من خلاّل توجيه سؤ ال للمبحوثين

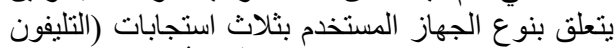

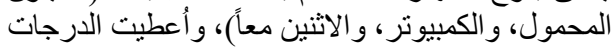

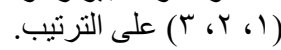

فترة التصفح لمواقع التواصل الترنب الاجتماعي: تم قياسه من

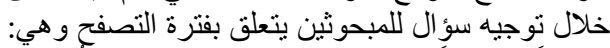

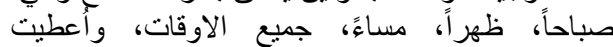

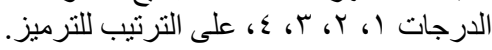

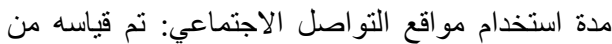

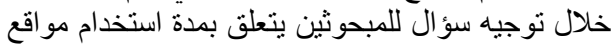

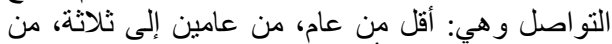

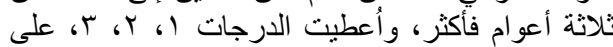

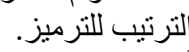

أماكن دخول تصفح مو اقع التو اصل الاجتماعي: تم قياسه

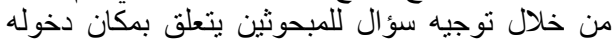

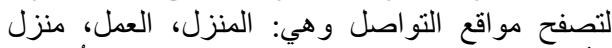

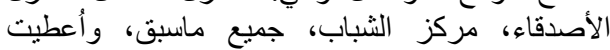

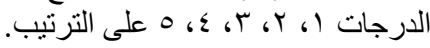
مستوى استخدام مواقع التواصل الاجتماعي: تم على قياسه

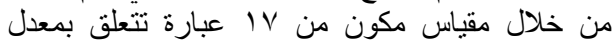

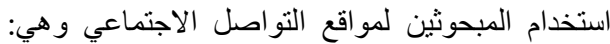

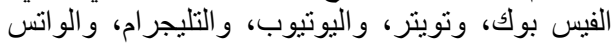

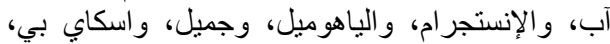

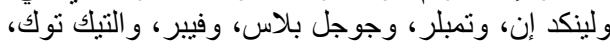

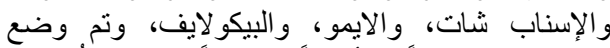

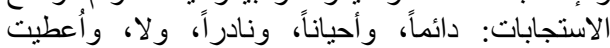

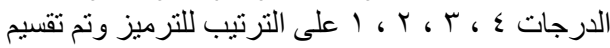

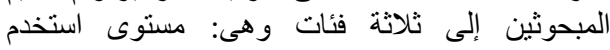




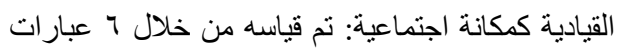

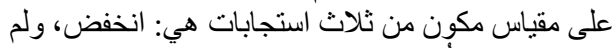

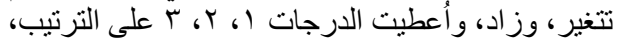

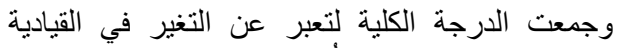

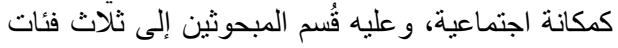

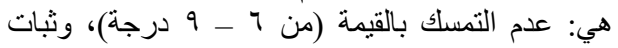

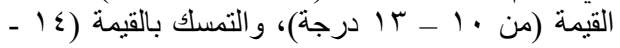

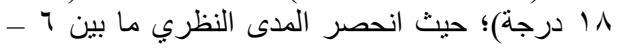

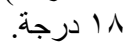

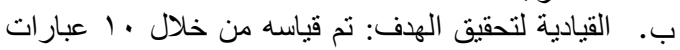

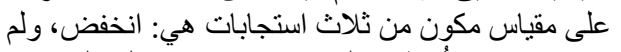

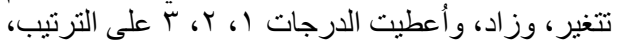

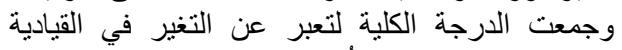

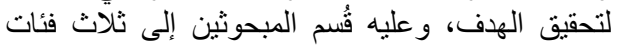

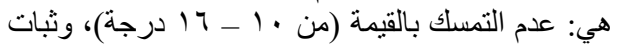

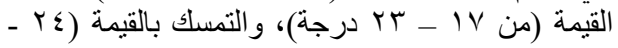

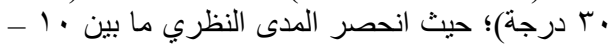

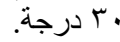

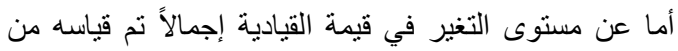

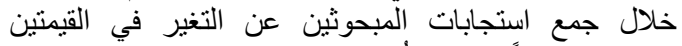

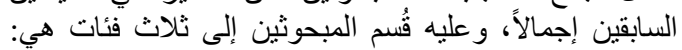

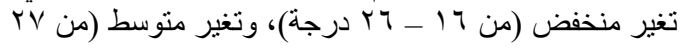

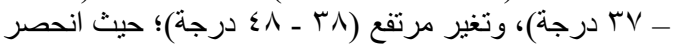

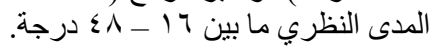

أما فيما يتعلق بمستوى التغير في القيم الاجتماعية اجمالاً نم

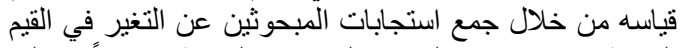

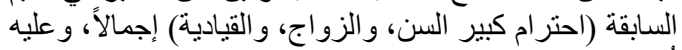

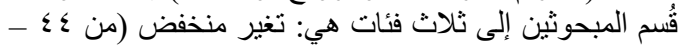

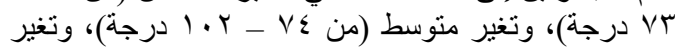

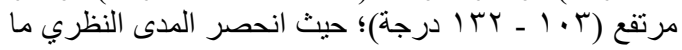

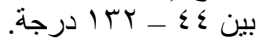

\section{النتائج ومناقشتها}

\section{أولا: وصف عينة البحث}

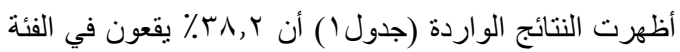

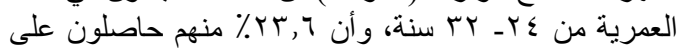

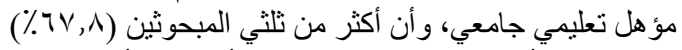

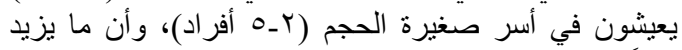

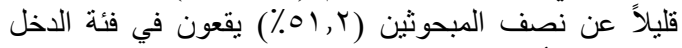

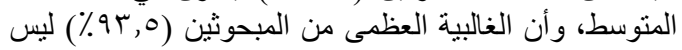

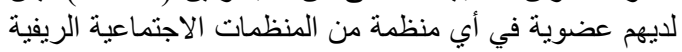

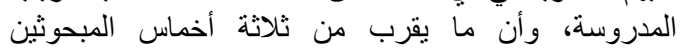
(نV, (1)
قيمة الزواج: تم قياس التغير في قيمة الزواج لدى لدئ

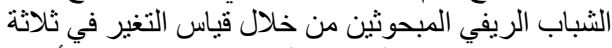

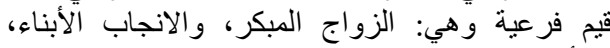

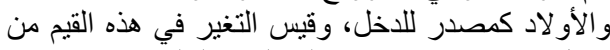

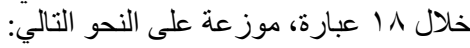

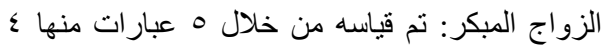

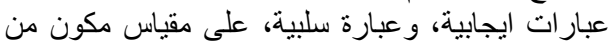

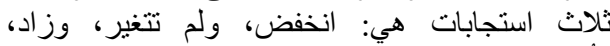

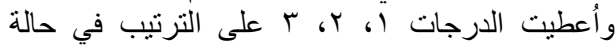

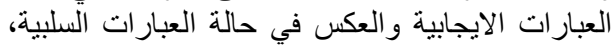

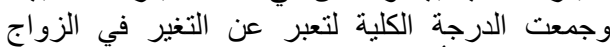

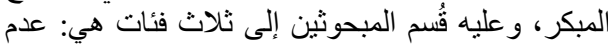

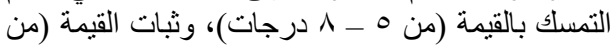

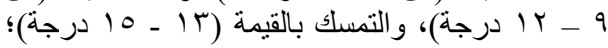

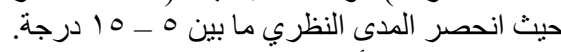

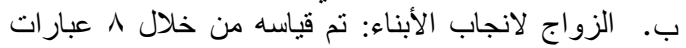

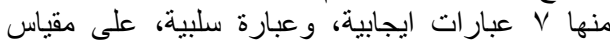

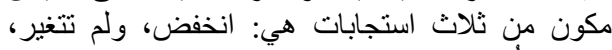

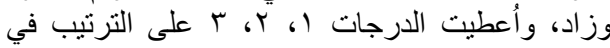

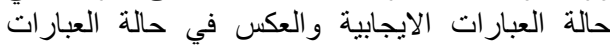

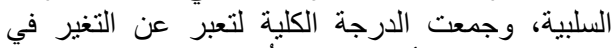

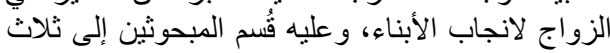

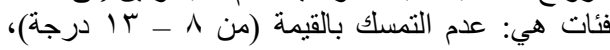

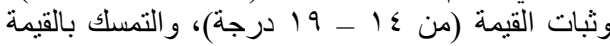

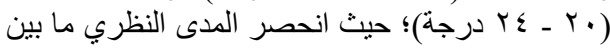

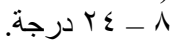
الأو لاد كمصدر للاخل: تم قياسه من خلال ه هبارة عبار ات

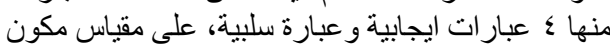

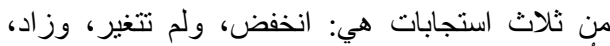

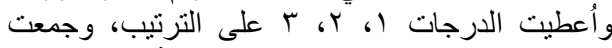

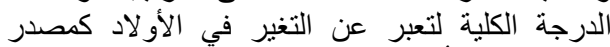

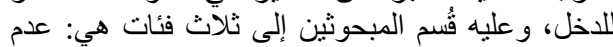

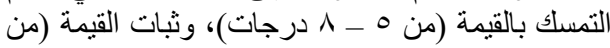

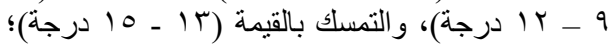

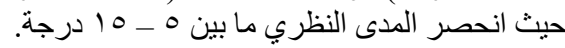
أما عن مستوى التغير في قيمة الزواج إجمالاً نم قياسه الفئه

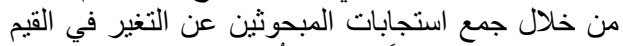

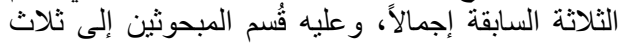

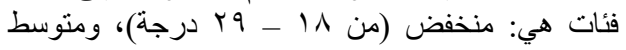

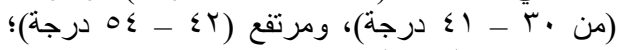

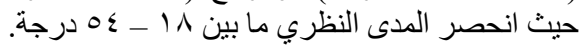

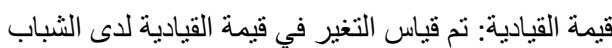

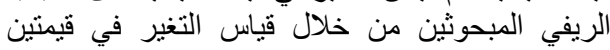

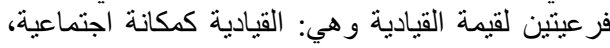

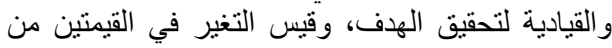
خلال 17 عبارة، موزعة على على النحو التالي: 
Abdallha et al. / Archives of Agriculture Sciences Journal 4(3) 11-25, 2021.

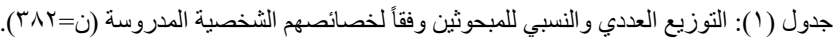

\begin{tabular}{|c|c|c|c|c|c|}
\hline$\%$ & عدد & الخصائص الثخصية & $\%$ & عدد & الخصائص الثخصية \\
\hline \multicolumn{3}{|r|}{ ع. متوسط دخل الأسرة الثهري . } & \multicolumn{3}{|r|}{ ا. السن } \\
\hline$r \Lambda, r$ & $1 \leqslant 7$ & 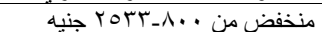 & $r 1,9$ & ITY & من 10 ــ أقل من rYTسنة \\
\hline $01, r$ & 197 & 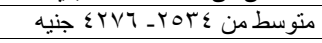 & $r \Lambda, r$ & $1 \leq 7$ & من 乏 Y- أقل من rاسنة \\
\hline 1,0 & $\varepsilon$. & مرتفع من & $r q, 1$ & $11 \varepsilon$ & من بr - •؛ سنة \\
\hline \multicolumn{3}{|r|}{ 0. العضوية في المنظمات الريفية } & \multicolumn{3}{|r|}{ r. المستوى التعليمي } \\
\hline \multirow{2}{*}{$9 \uparrow, 0$} & \multirow{2}{*}{ rov } & \multirow{2}{*}{ منخفضة من 7 ـ 9 درجات } & $\cdot, 0$ & r & أمي \\
\hline & & & $7, r$ & $r \varepsilon$ & يقر اءه ويكتب \\
\hline \multirow{2}{*}{$0, r$} & \multirow{2}{*}{ r. } & \multirow{2}{*}{ متوسطة من · اـ با درجة } & 0,0 & Y) & ابتدائي \\
\hline & & & 11,0 & $\varepsilon \varepsilon$ & اعدادي \\
\hline \multirow{2}{*}{$1, r$} & \multirow{2}{*}{0} & \multirow{2}{*}{ مرتفعة من ع | ـ ه| درجة } & $r_{\cdot}, \varepsilon$ & $V A$ & مؤ هل متوسط \\
\hline & & & 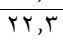 & 10 & مؤ هل فوق متوسط \\
\hline & & \multirow{2}{*}{ `. الانفتاح الثقافي } & $r T, T$ & 9. & مؤ هل جامعي \\
\hline & & & 9,9 & rA & در اسات عليا \\
\hline $9, \varepsilon$ & $r 4$ & منخفض من ع_ V درجات & & & r. عدد أفر اد الأسرة \\
\hline \multirow{2}{*}{ 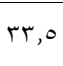 } & \multirow{2}{*}{ kr } & \multirow{2}{*}{ متوسط من ^ــ | الدرجة } & $T V, \Lambda$ & roq & من r ـ ـ أفر اد \\
\hline & & & $r \varepsilon, 9$ & 90 & من 7 - 9 أفراد \\
\hline $0 V, 1$ & YIA & مرتفع من Y ا_ ـ ادرجة & $V, r$ & rA & من · - Y rافرد \\
\hline
\end{tabular}

المصدر: استمارة الاستبيان.

المتاحة والمفضلة لاستخدام تصفح حساباتهم على مواقع التواصل الاجتماعي وذلك لتوافره بأسعار معقولة ولسهولة

$$
\text { حمله وخفة وزنه. }
$$

\section{r ـ فترة تصفح الشباب الريفي لمواقع التواصل الاجتماعي}

أسفرت النتائج الواردة (جدول ب) أن ما يقرب من نصف

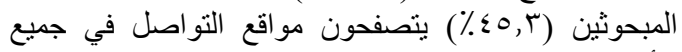

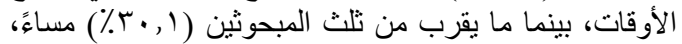

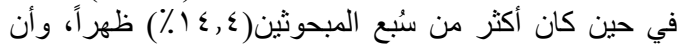

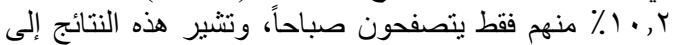

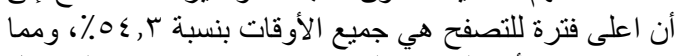

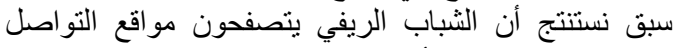
الاجتماعي في جميع الأوقات بنسبة كبيرة مما بيل الري

\section{ثانيا: تحديا درجة استخدام الشباب الريفي المبحوثين لمواقع

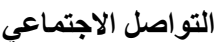

\section{ا ـ نوع الجهاز المستخدم في تصفح مواقع التواصل الاجتماعي}

بينت النتائج الو ادرة (جدول Y ( أن ما يقرب من ثلثي المبحوثين

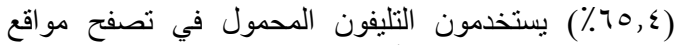

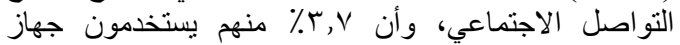

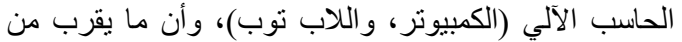

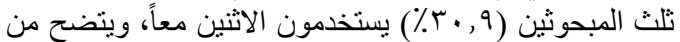

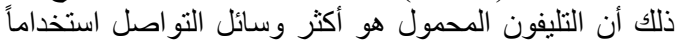

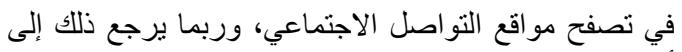

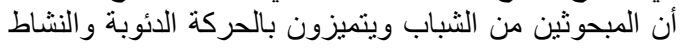
طول ساعات اليوم لذللك يعتبر التليفون المحمول هو الوسئن والئلة

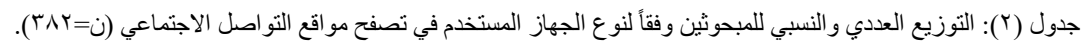

\begin{tabular}{|c|c|c|}
\hline$\%$ & عدد & نوع الجهاز المستخدم في تصفح مو اقع التو اصل الاجتماعي \\
\hline $70, \varepsilon$ & TO. & التليفون المحمول \\
\hline$r, V$ & $1 \varepsilon$ & جهاز الحاسب الآلي (الكمبيوتر، و اللاب توب) \\
\hline$r \cdot, q$ & 111 & الاثثنين معاً \\
\hline $1 \ldots$ & rAr & الإجمالى \\
\hline
\end{tabular}

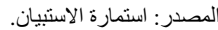

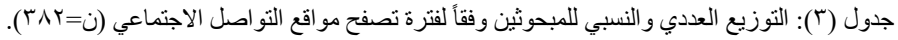

\begin{tabular}{|c|c|c|}
\hline$\%$ & عدد & فترة تصفح مو اقع التو اصل الاجتماعي \\
\hline $1 \cdot, r$ & r9 & صباحاً \\
\hline $1 \varepsilon, \varepsilon$ & 00 & ظهر أ \\
\hline$r \cdot, 1$ & 110 & مساءُ - مسء \\
\hline$\varepsilon 0, r$ & IVT & جميع الأوقات \\
\hline $1 \cdots$ & TAY & الإجمالي \\
\hline
\end{tabular}

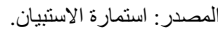




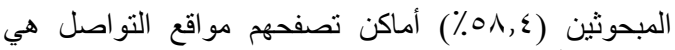

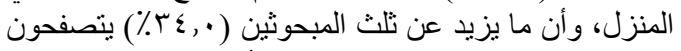

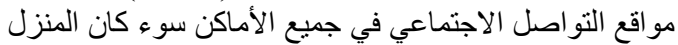

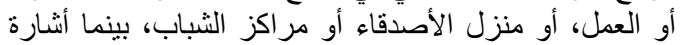

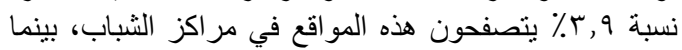

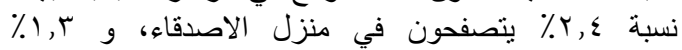

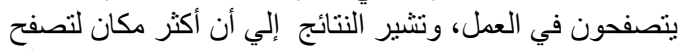

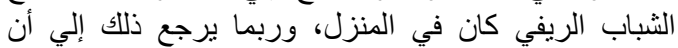

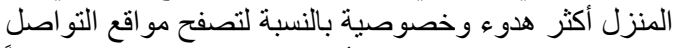

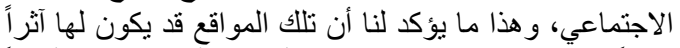

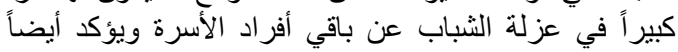

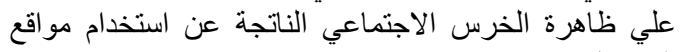

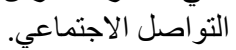

r. مدة استخدام مواقع التواصل الاجتماعي

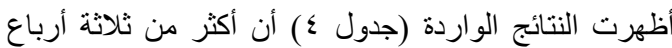

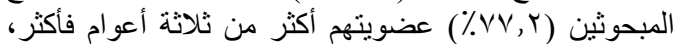

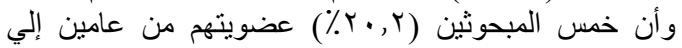

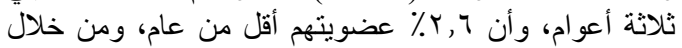

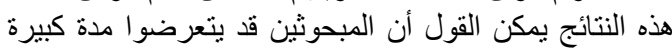

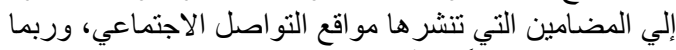

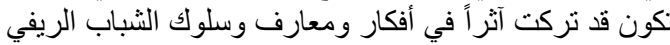
المستخدم لمو اقع التو اصل وبالتالتالي قد نؤدي إلي تغير قيمهر.

؛ . أماكن تصفح مواقع التواصل الاجتماعي

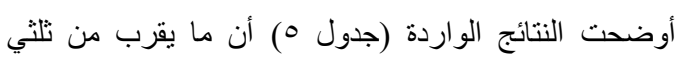

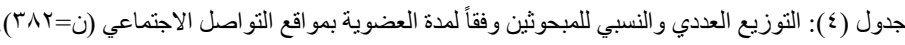

\begin{tabular}{|c|c|c|}
\hline$\%$ & عدد & مدة العضوية بمو اقع التو اصل الاجتماعي \\
\hline$r, T$ & 1. & أقلَ من عام . \\
\hline$\overline{Y \cdot, Y}$ & VV & من عامين إلي ثلاثة \\
\hline$V V, Y$ & r90 & من ثلاثة أعو ام فأكثر \\
\hline $1 \ldots$ & TAY & الإجمالي الي ال \\
\hline
\end{tabular}

المدر : استمارة الاستبيان.

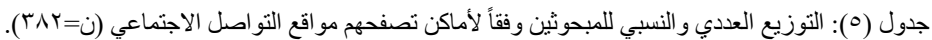

\begin{tabular}{|c|c|c|}
\hline$\%$ & عدد & أماكن تصفح المبحوثين لمو اقع التو اصل الاجتماعي \\
\hline $0 \wedge, \varepsilon$ & TYT & المنزل \\
\hline $1, r$ & 0 & العمل \\
\hline$T, \varepsilon$ & 9 & 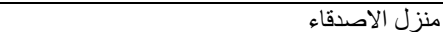 \\
\hline$r, 9$ & 10 & مر اكز الثباب \\
\hline$r \varepsilon, \cdot$ & 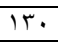 & جميع ما سبق \\
\hline $1 \cdots$ & TAY & الإجمالي \\
\hline
\end{tabular}

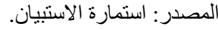

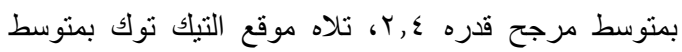

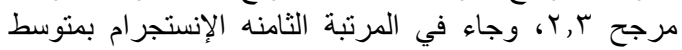

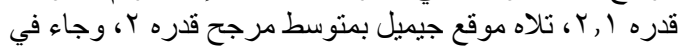

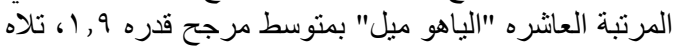

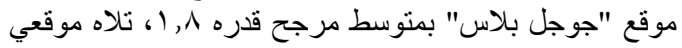

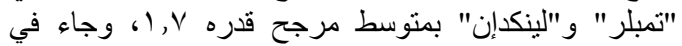

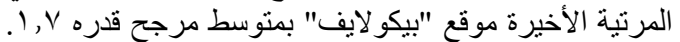

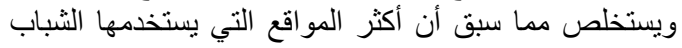

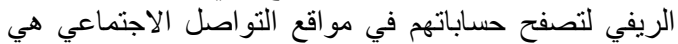
الفيس بوك، والايمو ، و الو اتس آب و والاسناب شات شات و اليوتيوب،

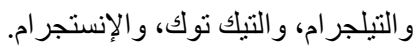

๑. مستوى استخدام مواقع التواصل الاجتماعي

أسفرت النتائج الواردة (جدول T) أن معدل استخدام الثباب

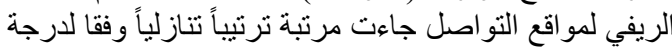

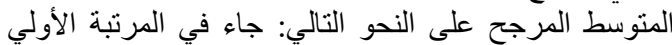

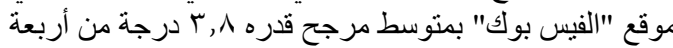

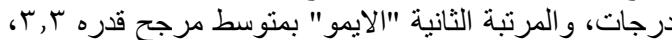

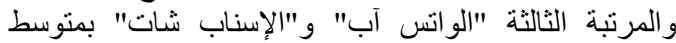

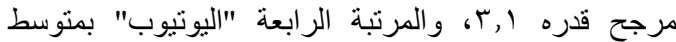

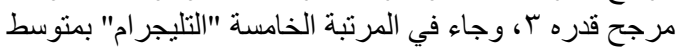

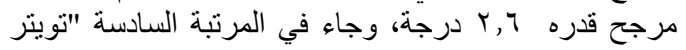


Abdallha et al. / Archives of Agriculture Sciences Journal 4(3) 11-25, 2021.

\begin{tabular}{|c|c|c|c|c|c|c|c|c|c|c|}
\hline \multirow{3}{*}{ الترتيب } & \multirow{3}{*}{ المرجح } & \multicolumn{8}{|c|}{ مستوى الاستخدام } & \multirow{3}{*}{ مو الاجع التواصل } \\
\hline & & \multicolumn{2}{|c|}{$\gamma$} & \multicolumn{2}{|c|}{ نادراً } & \multicolumn{2}{|c|}{ أحياناً } & \multicolumn{2}{|c|}{ دائماً } & \\
\hline & & $\%$ & عدد & $\%$ & عدد & $\%$ & عدد & $\%$ & عدد & \\
\hline 1 & $r, \Lambda$ & $V, 7$ & r9 & 0 & 19 & $9, \varepsilon$ & ry & $\vee \wedge$ & rqA & الفيس بوك \\
\hline 7 & $r, \varepsilon$ & $\Gamma, V$ & $|r|$ & Y1,0 & AY & $r \mu, r$ & 19 & $T r, T$ & 9. & تويتر \\
\hline$\varepsilon$ & $r$ & $9, r$ & ro & 19,1 & $V T$ & $r T, Y$ & ITV & $r \Lambda, 0$ & $1 \leqslant V$ & يوتيوب \\
\hline 0 & $r, 7$ & $r_{0, \varepsilon}$ & $9 V$ & 17,1 & $7 \varepsilon$ & $r V$ & 1.4 & $r \cdot, q$ & 111 & التليجر ام \\
\hline$r$ & $r, 1$ & $\Lambda, 7$ & rt & $1 \lambda, \lambda$ & $V Y$ & YY, $\varepsilon$ & 1.1 & $\sum 7,1$ & $1 V 7$ & الو اتس أب \\
\hline$\Lambda$ & $r, 1$ & $r \varepsilon,$. & $\pi$ & $r 9,7$ & $11 \pi$ & $r \varepsilon, 9$ & 90 & 11,0 & $\varepsilon \varepsilon$ & الإنستجر ام \\
\hline 1. & 1,9 & $\leq 7,1$ & $1 V 7$ & $r \leqslant, T$ & $9 \leq$ & $r \varepsilon, r$ & 94 & 0 & 19 & الياهو ميل \\
\hline 9 & r & $\varepsilon r, 1$ & 171 & Y I, & NT & $Y V, Y$ & $1 \cdot \varepsilon$ & $\Lambda, 9$ & $\Gamma \varepsilon$ & جيميل \\
\hline Ir & $1, v$ & 07 & YI & $r 1,0$ & $\lambda r$ & $10, \mathrm{~V}$ & 7. & $7, \wedge$ & YY & اسكاي بي \\
\hline מו & $1, V$ & $7 \cdot, V$ & rrT & $1 \lambda, 7$ & VI & $1 \pi, 7$ & Or & $v, 1$ & $T V$ & لينكد إن \\
\hline rا & $1, V$ & $7 \cdot, \mathrm{V}$ & YTY & $I V, 0$ & $7 V$ & $10, Y$ & 01 & 7,0 & To & تمبلر \\
\hline 11 & 1,1 & $0 \leqslant, Y$ & $Y \cdot V$ & $1 \wedge, 1$ & $V Y$ & IV & 70 & 9,9 & rᄉ & جوجل بلاس \\
\hline $3^{9}$ & $r$ & $\sum 0, r$ & IVT & $r \Gamma, T$ & 9. & $11, r$ & $V \cdot$ & $I Y, \Lambda$ & $\sum 9$ & فيير \\
\hline $\mathrm{V}$ & $r, r$ & $\varepsilon r, q$ & $17 \varepsilon$ & $1 \pi, 1$ & 0. & 17,1 & $7 \varepsilon$ & $T V, Y$ & $1 \cdot \varepsilon$ & التيك توك \\
\hline Tr & $r, 1$ & $10, \varepsilon$ & 09 & $\Lambda, 7$ & Tr & TY,O & $\Lambda 7$ & Or, \& & $r \cdot \varepsilon$ & الإسناب شات \\
\hline$r$ & $r, r$ & $1 \cdot, r$ & $r 9$ & $1 \cdot, V$ & $\sum 1$ & $T Y, 0$ & $\Lambda T$ & 07,0 & Y17 & الايمو \\
\hline \multirow[t]{2}{*}{14} & 1,0 & $v 9,1$ & $r \cdot r$ & $r, \varepsilon$ & 9 & $V, 7$ & rq & 11 & $\sum r$ & بيكو لايف \\
\hline & $r, r$ & \multicolumn{9}{|c|}{ المتوسط المرجح الإجمالّ } \\
\hline
\end{tabular}

المصدر: استمارة الاستبيان.

مايزيد بقليل عن خمس (0, •r\%) المبحوثين كانت درجة

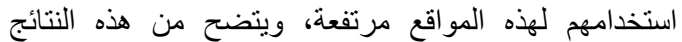

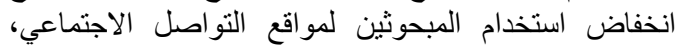

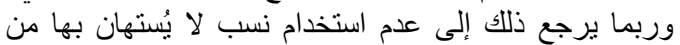

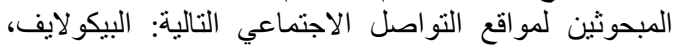

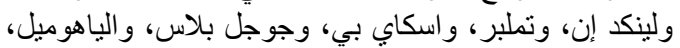

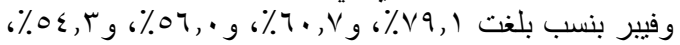

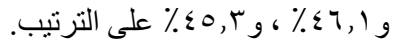

\section{T. مستوى استخدام الثباب الريفي لمواقع التواصل الاجتماعي إجمالاً}

أما فيما يتعلق بمستوى استخدام الثباب الريفي المبحوثين

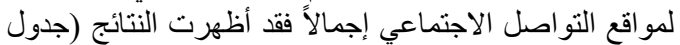

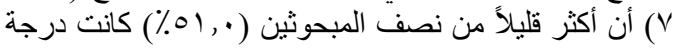

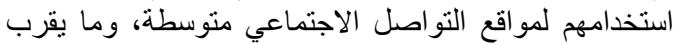

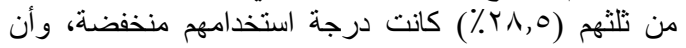

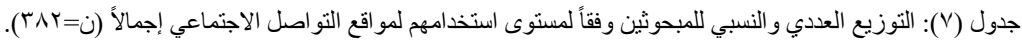

\begin{tabular}{|c|c|c|}
\hline$\%$ & عدد & مستوى استخدام الثباب الريفي المبحوثين لمو اقع التو اصل الاجتماعي إجمالًا \\
\hline$r \Lambda, 0$ & 1.9 & مستوى استخذام منخفض \\
\hline $01, \cdot$ & 190 & مستوى استخدام متوسط \\
\hline$r \cdot, 0$ & $\nabla \wedge$ & مستوى استخدام مرتفع \\
\hline $1 \cdots$ & TAY & الإجمالي \\
\hline
\end{tabular}

المصدر : استمارة الاستبيان.

نصف المبحوثين ( • , \%1\%) درجة استخدامهم لمواقع التو اصل الاجتماعي متوسطة.

\section{ثالثا: التغير في القيم الاجتماعية في ظل استخدام مواقع التواصل الاجتماعي في التئ}

تم قياس التغير في القيم الاجتماعية من خلال مجمو عة من القيم

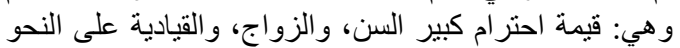

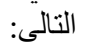

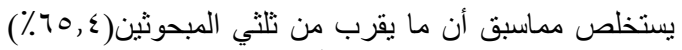

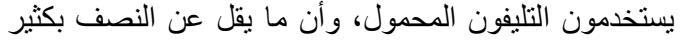

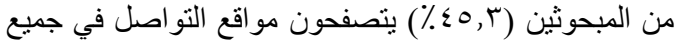

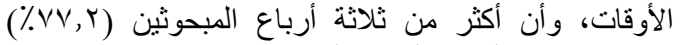

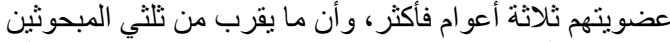

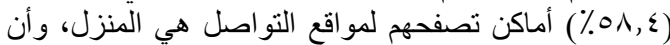

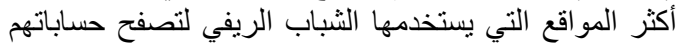

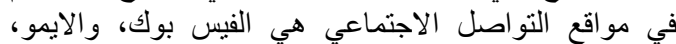

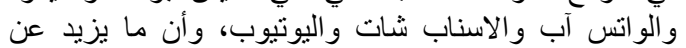


إمكانياتها، وقد تربوا على احترام كبير السن، وطاعته، وتنفيذ آراؤه.

ب. تفضيل تقديمه: بينت النتائج الواردة (جدول م) أن تفضيل

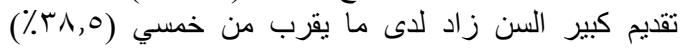

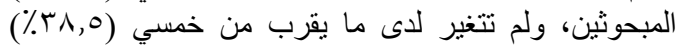

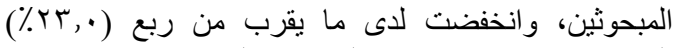

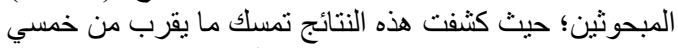

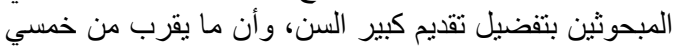

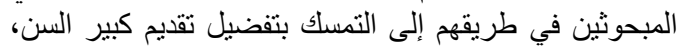

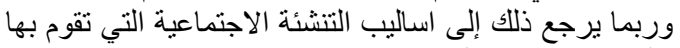

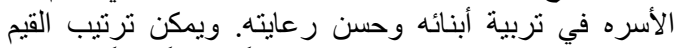

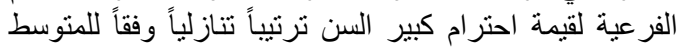

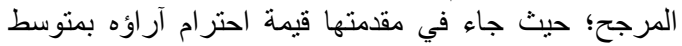

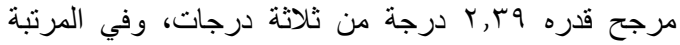

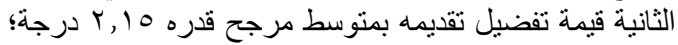

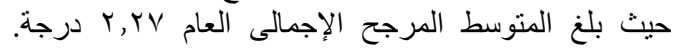

1 ـ قيمة احترام كبير السن

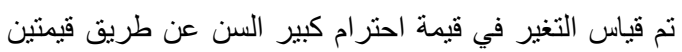

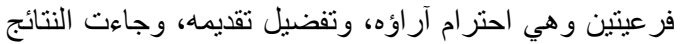
الخاصة بالتغير في كل قيمة فر آرية ولثية على النحو التالي:

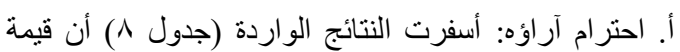

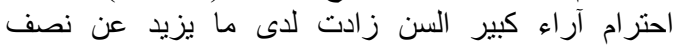

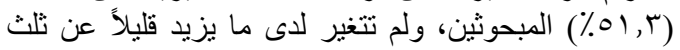

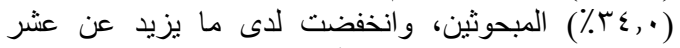

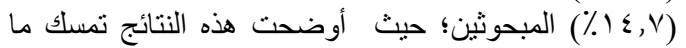

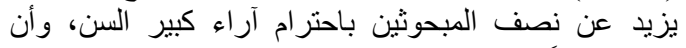

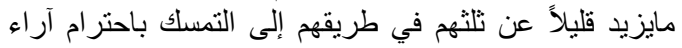

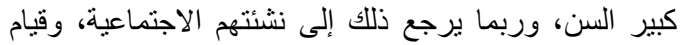

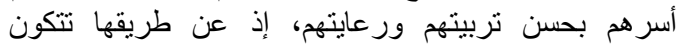

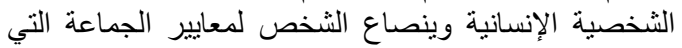

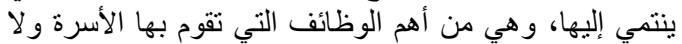
تسنظيع أبي مؤسسة أخري أن تقوم بها بذّات الكفاءة مهما كانت الأن

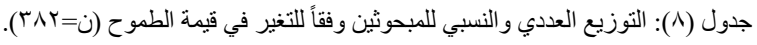

\begin{tabular}{|c|c|c|c|c|c|c|c|c|}
\hline \multirow{3}{*}{ الترتييب } & \multirow{3}{*}{ المتوسط المرجح } & \multicolumn{6}{|c|}{ التغير في قيمة احتر ام كبير السن } & \multirow{3}{*}{ القيم الفر عية } \\
\hline & & \multicolumn{2}{|c|}{ انخفض } & \multicolumn{2}{|c|}{ لم لم تتغير } & \multicolumn{2}{|c|}{ زاد } & \\
\hline & & $\%$ & 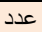 & $\%$ & عدد & $\%$ & عدد & \\
\hline 1 & $r, r q$ & $1 \varepsilon, V$ & 70 & $r \varepsilon,$. & $\pi$. & $01, r$ & 197 & احتر ام أر اؤه \\
\hline r & $r, 10$ & $r T,$. & $\Lambda \wedge$ & $r \Lambda, 0$ & $1 \leqslant V$ & $\Gamma \Lambda, 0$ & $1 \leqslant V$ & تفضبل تقديمه \\
\hline \multicolumn{2}{|c|}{$T, Y V$} & \multicolumn{7}{|c|}{ المتوسط المرجح العام } \\
\hline
\end{tabular}

المدر : استمارة الاستبيان.

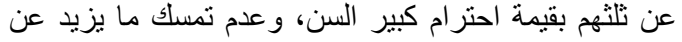

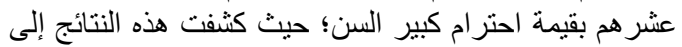
تمسك ما بزيد عن ثلث المبحوثين بقيمة احترام كبير السن السن،

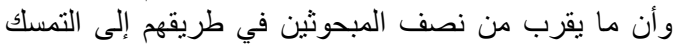

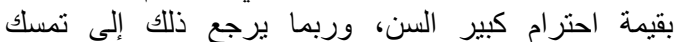
المبحوثين بالقيم الفرعية لقيمة احترام كبير القبير السن (احترام

آرؤه، و تفضيل تقديمة).
أما فيما يتعلق بمستوى التغير في قيمة احترام كبير السن

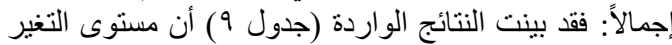

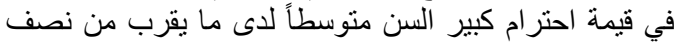

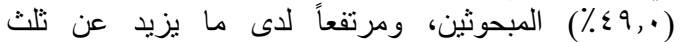

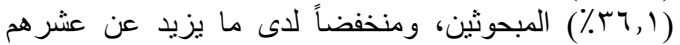

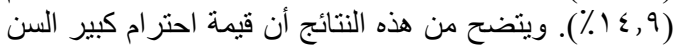

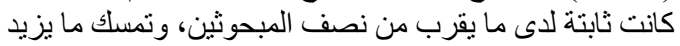

\begin{tabular}{|c|c|c|}
\hline$\%$ & عدد & مستوى التغير في قيمة احتر ام كبير السن إجمالاً \\
\hline $1 \leqslant, 9$ & or & منخفض (عدم التمسك بالقيمة) \\
\hline$\sum 9$, & INV & متوسط (ثبات القيمة) \\
\hline$r 4,1$ & 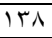 & مرتفع (التمسك بالقيمة) \\
\hline $1 \ldots$ & TAY & الإجمالى \\
\hline
\end{tabular}

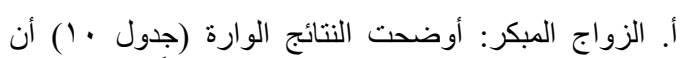

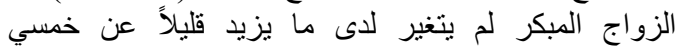

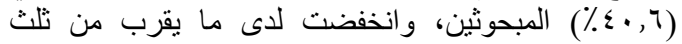

تم قياس التغير في قيمة الزواج عن طريق ثناث قيم فرعية

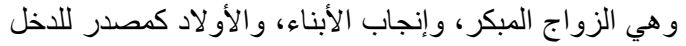

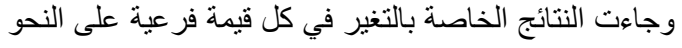




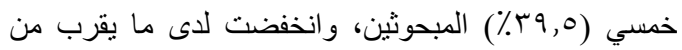

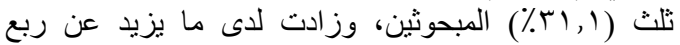

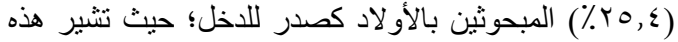

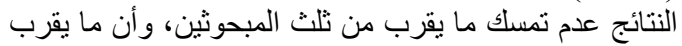

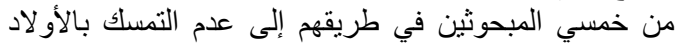

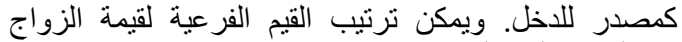

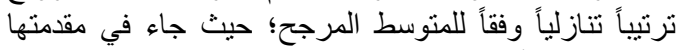

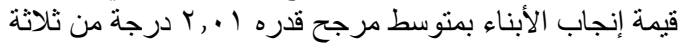

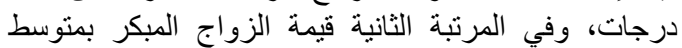

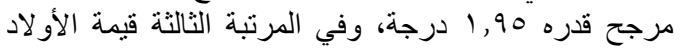

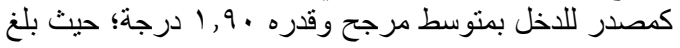
المتوسط المرجح الإجمالى العام 90 , 1 درجة.

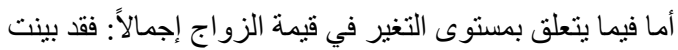

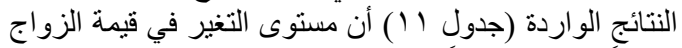

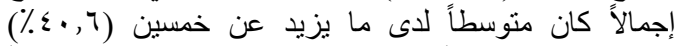

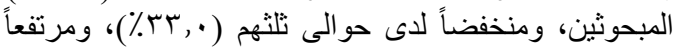

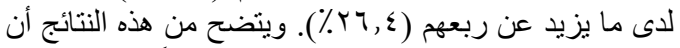

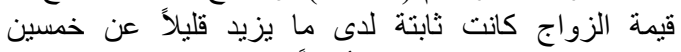

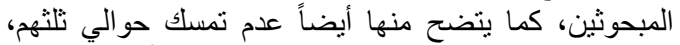

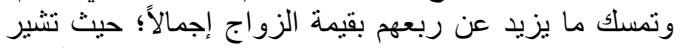

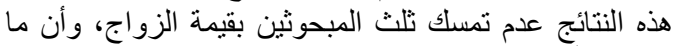

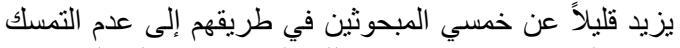

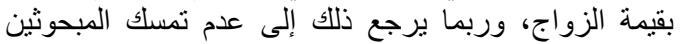

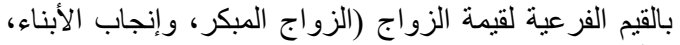

و لأو لاد كمصدر للألخد).

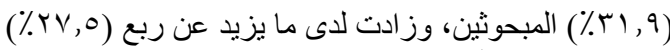

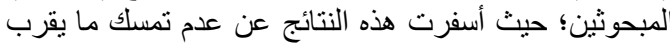

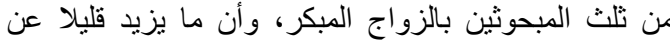

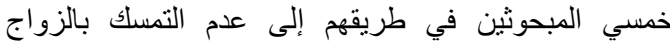

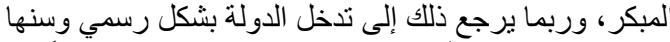

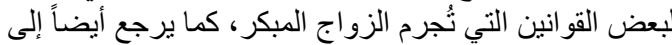

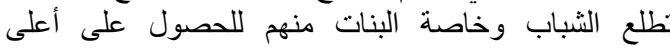

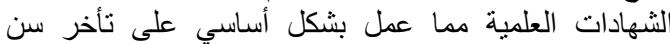

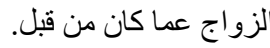

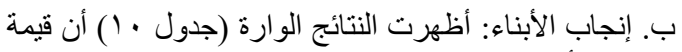

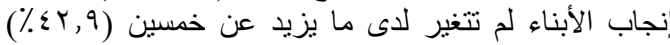

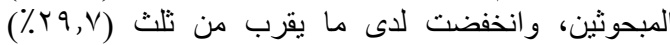

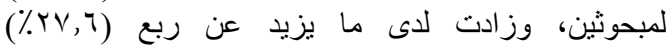

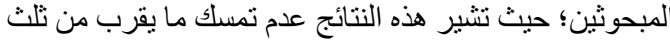

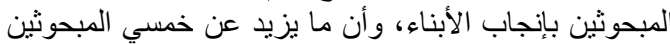

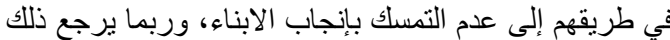

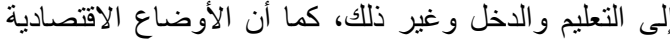

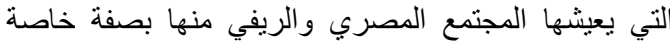

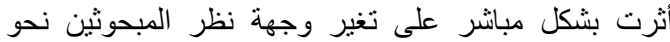

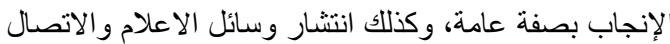

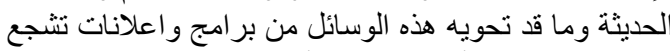

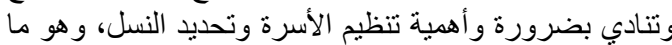
أدي بشكل أو آخر إلى خفض عضل عدد الأبناء بالأسرة.

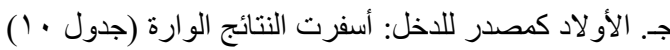

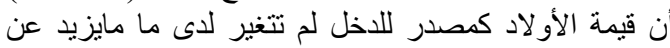

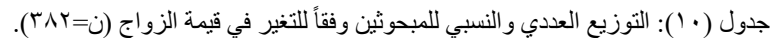

\begin{tabular}{|c|c|c|c|c|c|c|c|c|}
\hline \multirow{3}{*}{ الترتيبب } & \multirow{3}{*}{ المتوسط المرجح } & \multicolumn{6}{|c|}{ التغير في قيمة الزواج } & \multirow{3}{*}{ القيم الفرعية } \\
\hline & & \multicolumn{2}{|c|}{ انخفض } & \multicolumn{2}{|c|}{ لم لمتغير } & \multicolumn{2}{|c|}{ زاد } & \\
\hline & & $\%$ & عدد & $\%$ & عدد & $\%$ & عدد & \\
\hline r & 1,90 & $r 1,9$ & IYY & $\varepsilon \cdot$, & 100 & $Y V, 0$ & 1.0 & الزواج المبكر \\
\hline 1 & $r, \cdot 1$ & $r q, V$ & TYY & $\varepsilon r, q$ & $17 \varepsilon$ & $Y V, V$ & 1.7 & إنجاب الأبناء \\
\hline$r$ & $1,9$. & $\Gamma, 1$ & $\pi \varepsilon$ & $r 9,0$ & 101 & To, & $9 \mathrm{~V}$ & الأو لاد كمصدر للاخل \\
\hline \multicolumn{2}{|r|}{1,90} & \multicolumn{7}{|c|}{ المتوسط المرجح العام } \\
\hline
\end{tabular}

المصدر : استمارة الاستبيان.

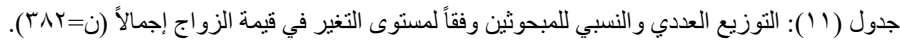

\begin{tabular}{|c|c|c|}
\hline$\%$ & عدد & مستوى التغير في قيمة الزواج إجمالاً \\
\hline$r \mu, \cdot$ & $1 Y 7$ & منخفض (عدم التمسك بالقيمة) \\
\hline$\varepsilon \cdot, \uparrow$ & 100 & متوسط (ثبات القيمة) \\
\hline ห५, ६ & 1.1 & مرتفع (التمسك بالقيمة) \\
\hline $1 \ldots$ & TAY & الإجمالي \\
\hline
\end{tabular}

المصدر : استمارة الاستبيان.

وجاءت النتائج الخاصة بالتغير في كل قيمة فرعية على النحو التالي: أ. القيادية كمكانة اجتماعية: أسفرت النتائج الواردة (جدول r. قيمة القيادية

تم قياس التغير في قيمة القيادية عن طريق قيمتين فرعيتين

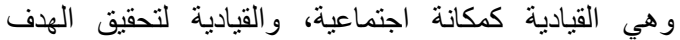




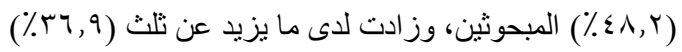

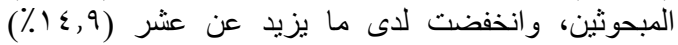

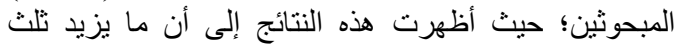

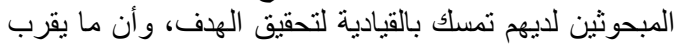
من نصف المبحوثين في طريقه إلى التمسك بالقيادية التئية لتحقيق

الهدف.

ويمكن ترتيب القيم الفرعية لقيمة القيادية ترنيباً تنازلياً وفقاً

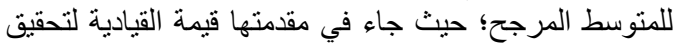

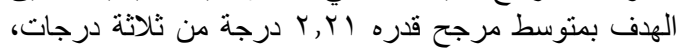

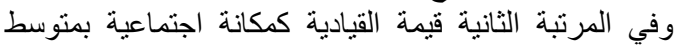

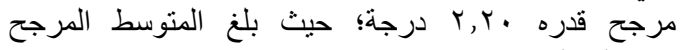

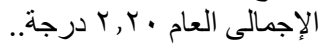

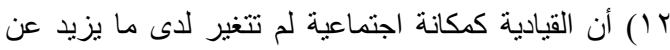

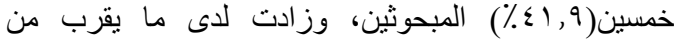

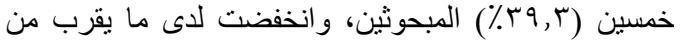

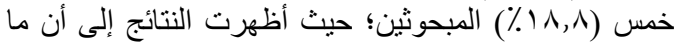
يقرب من خمسين المبحوثين كان لايهم تمسك بالقين بالقيادية كمكانة

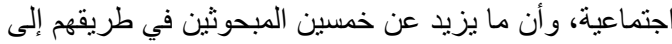

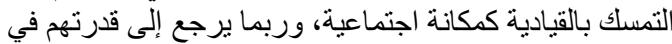
التحكم في سلوك الأخرين وتوجيهوم نحو أفكار معينة، نظراً

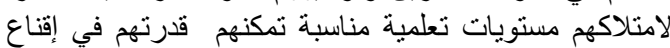

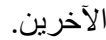

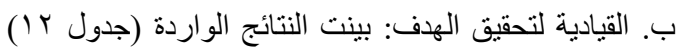
أن القيادية لتحقيق الهدف لم تتغير لالى ما يقرب من نصف لون

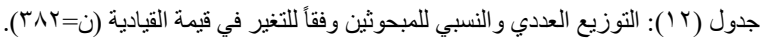

\begin{tabular}{|c|c|c|c|c|c|c|c|c|}
\hline \multirow{3}{*}{ الترتييب } & \multirow{3}{*}{ المتوسط المرجح } & \multicolumn{6}{|c|}{ التغير في قيمة القيادية } & \multirow{3}{*}{ لقيم الفر عية } \\
\hline & & \multicolumn{2}{|c|}{ 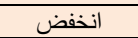 } & \multicolumn{2}{|c|}{ لَّ تلتغير } & \multicolumn{2}{|c|}{ زاد } & \\
\hline & & $\%$ & عدد & $\%$ & عدد & $\%$ & عدد & \\
\hline r & $r, Y$. & $1 \lambda, \lambda$ & $V Y$ & $\leqslant 1,9$ & 17. & $r q, r$ & 10. & القيادية كمكانة اجتماعية \\
\hline 1 & $r, Y I$ & $1 \leqslant, 9$ & ov & $\varepsilon \wedge, Y$ & $1 \wedge \varepsilon$ & $r 4,9$ & $1 \leq 1$ & القيادية لتحقيق الهدف \\
\hline \multicolumn{2}{|r|}{$Y, Y}$. & \multicolumn{7}{|c|}{ المتو سط المرجح العام } \\
\hline
\end{tabular}

المصدر : استمارة الاستبيان.

تتميز بالثبات لأى ما يزيد عن نصـف المبحـوثين، كمـا يتضـح

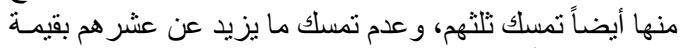

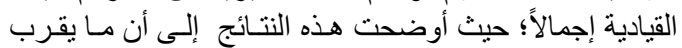

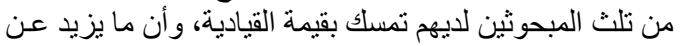

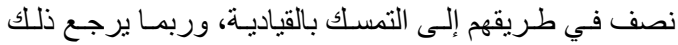
الارتفاع إلى تمسكهم بالقيادية كمكانة اجتماعية، ولتحقيق الهدف.

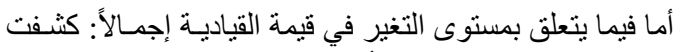

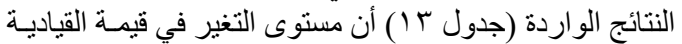

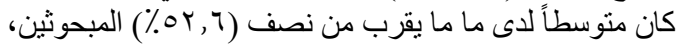

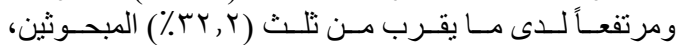

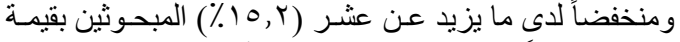

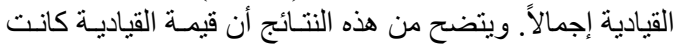

\begin{tabular}{|c|c|c|}
\hline$\%$ & عدد & مستوى التغير في قيمة القيادية إجمالاً \\
\hline $10, Y$ & 01 & منخفض (عدم التمسك بالقيمة) \\
\hline or, 1 & $r \cdot 1$ & متوسط (ثبات القيمة) \\
\hline$r r, r$ & ITr & مرتفع (التمسك بالقيمة) \\
\hline $1 \ldots$ & rAY & الإجمالي \\
\hline
\end{tabular}

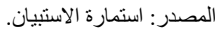

بمستوى التغير في القيم الاجتماعيـة إجمـالاً: فقد بينـت النتـائج الواردة (جدول

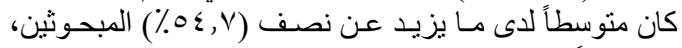

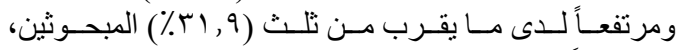

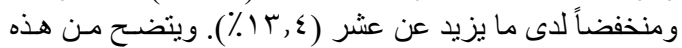

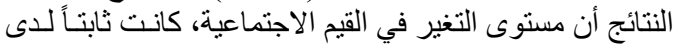

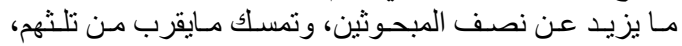

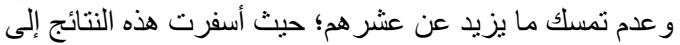

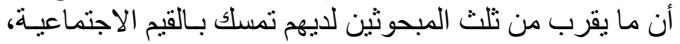

\section{ع. التغير في القيم الاجتماعية المدروسة}

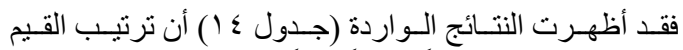

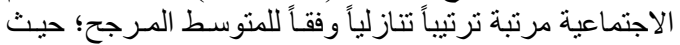

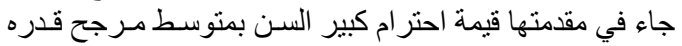

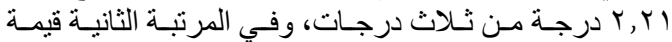

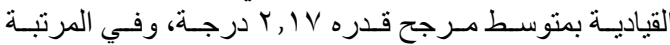

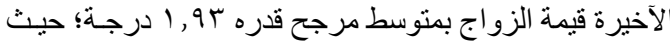

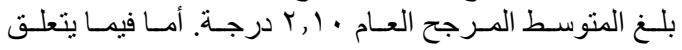




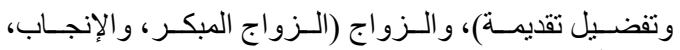

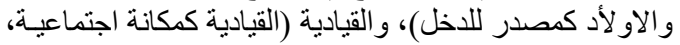
ولتحقيق الهدف).

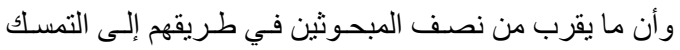

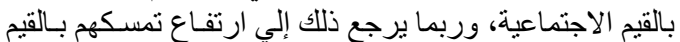

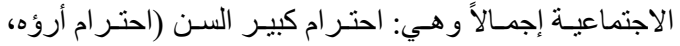

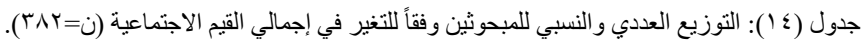

\begin{tabular}{|c|c|c|c|c|c|c|c|c|}
\hline \multirow{3}{*}{ الترتييب } & \multirow{3}{*}{ المتوسط المرجح } & \multicolumn{6}{|c|}{ التغير في القيم الاجتماعية إجمالً } & \multirow{3}{*}{ القيم } \\
\hline & & \multicolumn{2}{|c|}{ انخفض } & \multicolumn{2}{|c|}{ لم لمتغير } & \multicolumn{2}{|c|}{ زاد } & \\
\hline & & $\%$ & عدد & $\%$ & عدد & $\%$ & عدد & \\
\hline 1 & $Y, Y$, & $1 \leqslant, 9$ & ov & $\sum 9, \cdot$ & IAV & $r 4,1$ & $1+1 \mathrm{~A}$ & احترام كبير السن \\
\hline$r$ & 1,94 & $r \mu,$. & $1 \times 4$ & $\varepsilon, 4$ & 100 & $r q, \varepsilon$ & 1.1 & قيمة الزواج \\
\hline$r$ & T,IV & $10, Y$ & 01 & or,, 1 & $r+1$ & 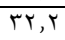 & ITr & قايمة القبادية \\
\hline \multicolumn{2}{|r|}{$\overline{r, l}$} & \multicolumn{7}{|c|}{ ل } \\
\hline
\end{tabular}

المصدر : استمارة الاستبيان.

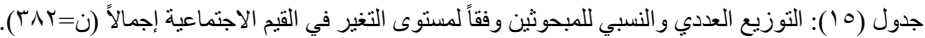

\begin{tabular}{|c|c|c|}
\hline$\%$ & عدد & مستوى التغير في القيم الاجتماعية إجمالاً \\
\hline $1 T, \varepsilon$ & 01 & منخفض (عدم التمسك بالقيمة) \\
\hline $0 \leqslant, V$ & $r \cdot 9$ & متوسط (ثبات القيمة) \\
\hline ri, 9 & IYY & مرتفع (التمسك بالقيمة) \\
\hline $1 \cdots$ & thit & الإجمالي \\
\hline
\end{tabular}

المصدر : استمارة الاستبيان.

رابعا: العلاقة بين مستوى استخدام الثباب الريفي لمواقع (لسبيرمان) وجاءت النتائج على النحو النالي (جدول 7 (1):

وجود علاقة ارتباطية طردية عند مستوى معنويـة ا ل, ـ.

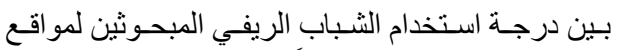

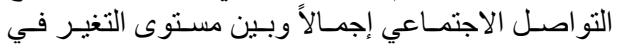
إجمالى قيمة القبادية.

وجود علاقة ارتباطية طردية عند مستوى معنويـة م. . . .

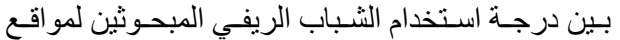

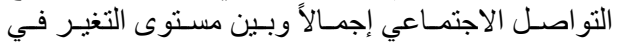
إجمالي القيم التالية: احترام كبير السن، والزئ الزواج.
رابعا: العلاقة بين مستوى استخدام الثباب الريفي لمواقع

لتحديد العلاقة بين درجـة استخدام الثباب الريفي المبحوثين

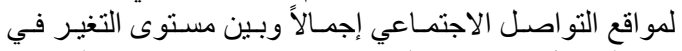

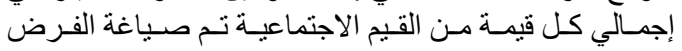

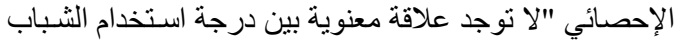

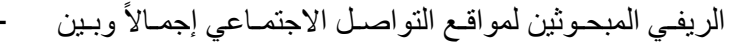

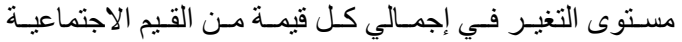

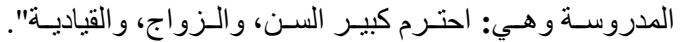

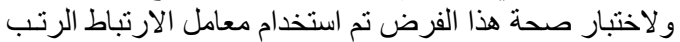

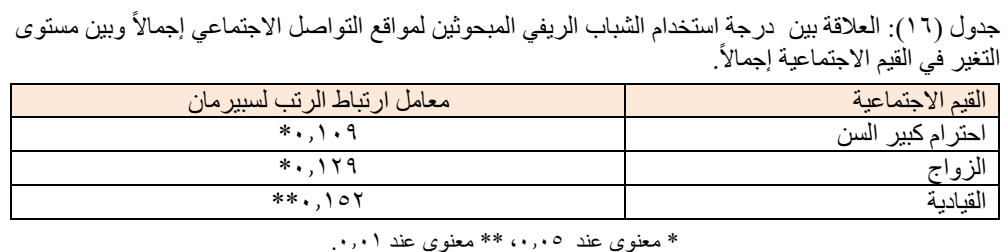

النتائج عن وجود علاقة ارتباطية معنوية بين درجة استخدام

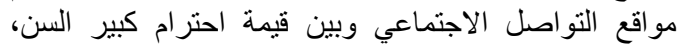

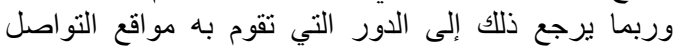

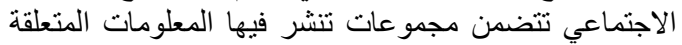

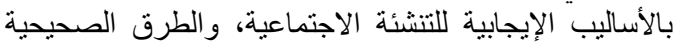
لتربية الأبناء، ومنها احترام كبير السن. وألإئه وضحت هذه النتائج
وبناءً على هذه النتائج يمكن رفض الفرض الاحصيائي بالنسبة

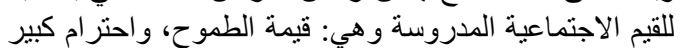

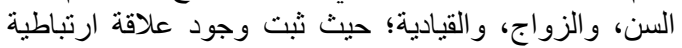

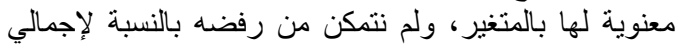

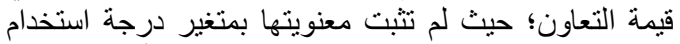

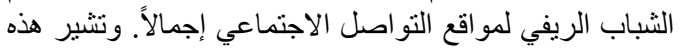


والتطبيق، دار مجدلاوي للنشر و الطباعة، عمان،

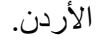

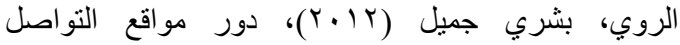
الاجتماعي في التغير "مدخل نطري"، بـابل مجلة كلية

الاعلام، جامعة بغداد، العر اق.

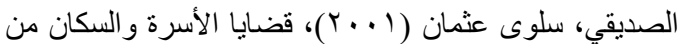

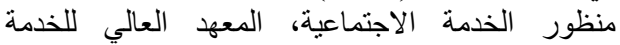

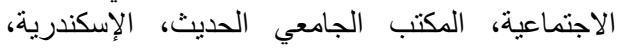
جمهورية مصر العربية.

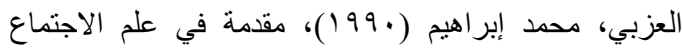
الريفي، كلية الزراعة، جامعة الإسكندرية، دار المعارف الإف الجامعية، جمهورية مصر العربية.

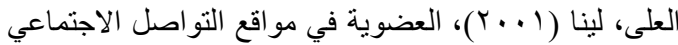

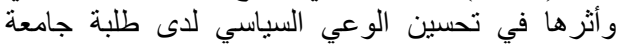
النجاح الوطنية، رسالة ماجستير، كلية الاقتصساد و العلوم لإنية

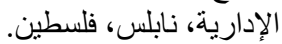

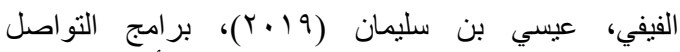
الاجتماعي، دار الخليج للنشر والتوزيع، الأردن.

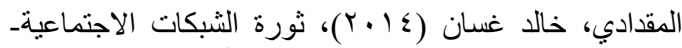

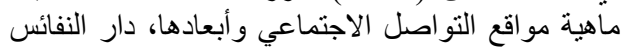
للنشر و التوزيع، الطبعة رقم الو الـ الأردن.

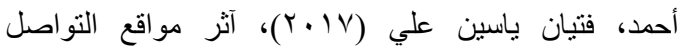

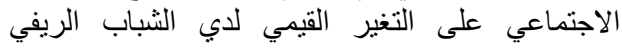

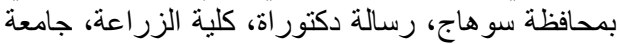
أسيوط، جمهورية مصر العربية.

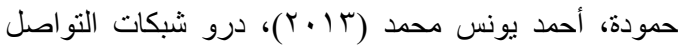

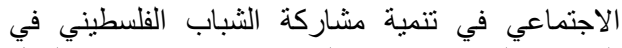

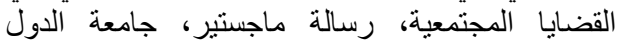

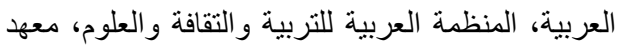

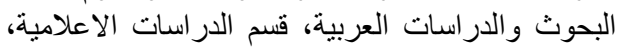
القاهرة، جمهورية مصر العربية.

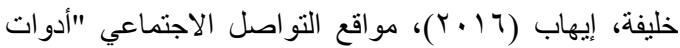

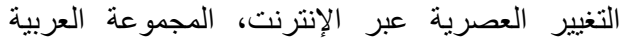
للتنريب والنشر، الطبعة الأولى، القاهرة، جمهورية النية

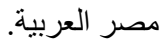

داود، رضا محمود محمد (T + . Y)، التوجهات القيمية للثباب

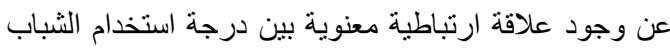

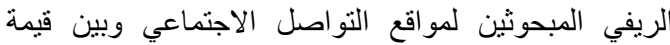

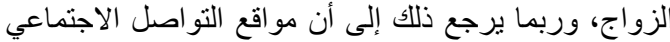

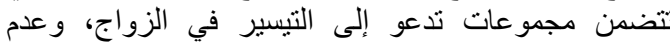

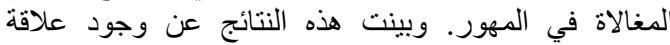

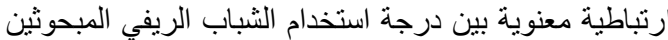

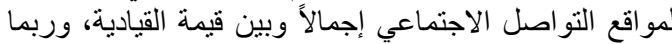

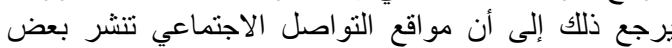

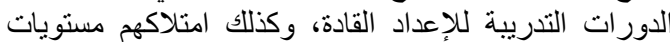

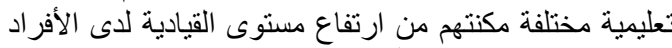

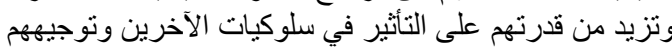

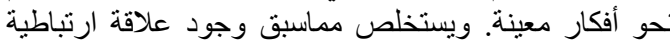

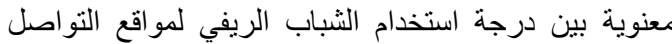

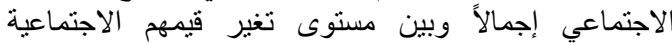
المدروسة وهي: احتر ام كبير السن، الزواجن، والقين فئيادية.

\section{توصيات البحث}

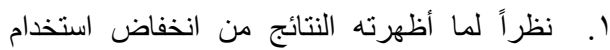

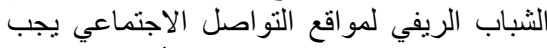

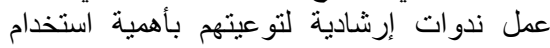

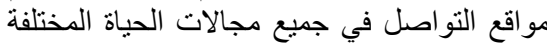
بشكل إيجابي.

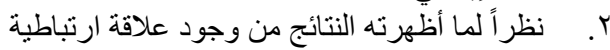

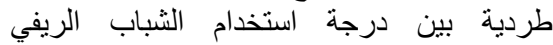

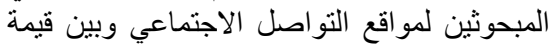

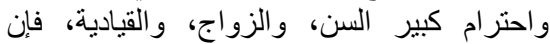

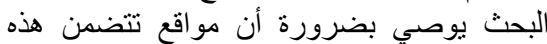

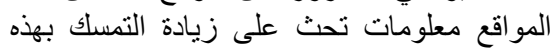

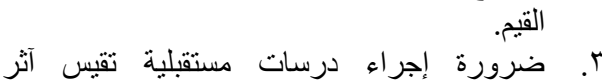
التحو لات المجتمعية الآخرى غير مو اقع التواصل الاجتماعي على القيم الاجتماعية المدروسئة

\section{قائمة المراجع أولاً: المراجع العربية}

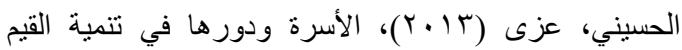
الاجتماعية لاى الطفل في مرحلة الطفولة المتألة الطرة: دراسة ميدانية لعينة من تلاميذ الطئة السنة الخامسة ابتدائي

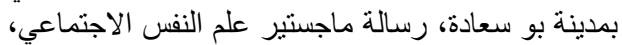

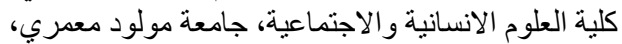

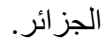

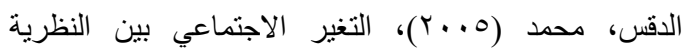




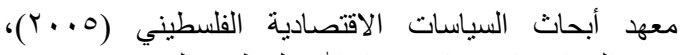

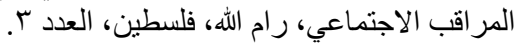

$$
\begin{aligned}
& \text { وهدان، نادرة، زينات طلبة، عزيزة عبدالرازق، مني دسوقي، }
\end{aligned}
$$

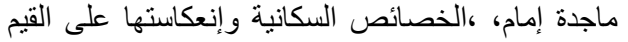

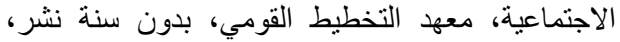

$$
\begin{aligned}
& \text { القاهرة، جمهورية مصر العربية. }
\end{aligned}
$$

الريفي بمحافظة المنوفية، رسالة دكثور اة، كلية الزر اعة،

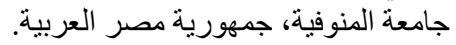

عبدالحميد، زينب، ووسام القصاص، (10 ب ب) دراسة مقارنة

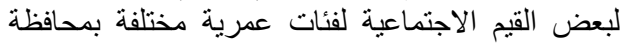

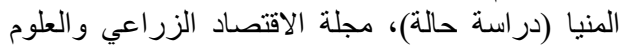

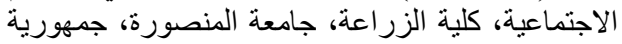

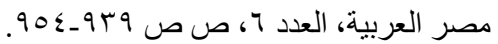

ثانياً: المراجع الإتجليزية

Roos, F. (1977), Human Needs and Politics, Pergamon Press, United Kingdom.

Krejcie, V. and Morgan D. W. (1970), "Determining sample size for research activities", Educational and Psychological Measurement, Vol. 30, pp. 607-610. 